\title{
Consumers in the Circular Economy
}

Essays on Extending Product Lifecycles

Emma Salminen

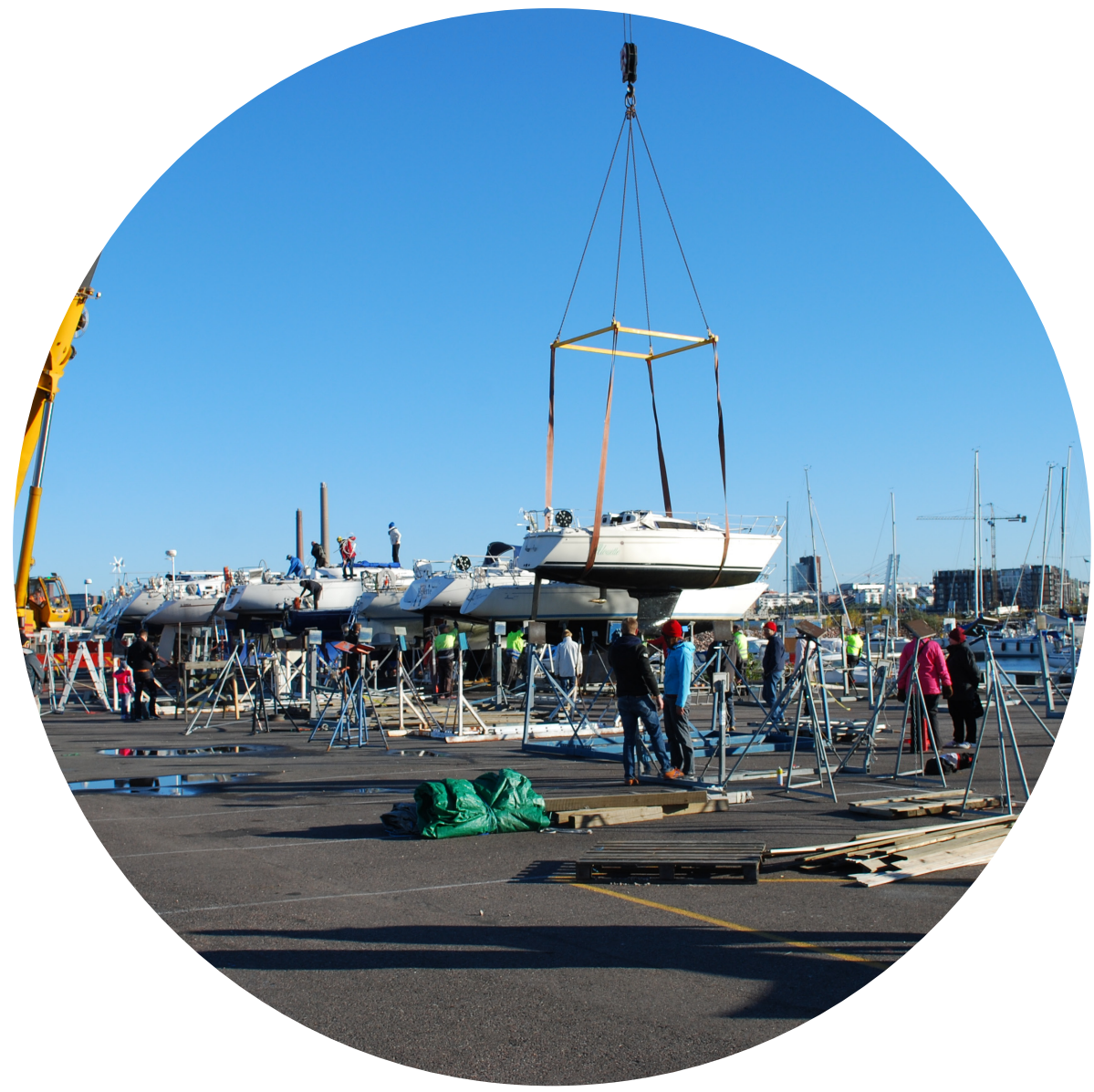




\section{Consumers in the Circular Economy}

Essays on Extending Product Lifecycles

\section{Emma Salminen}


Professor Henri Weijo, Aalto University School of Business, Finland

\section{Preliminary examiners}

Professor Benjamin Hartmann, University of Gothenburg, Sweden

Professor Andrea Prothero, University College Dublin, Ireland

\section{Opponent}

Professor Benjamin Hartmann, University of Gothenburg, Sweden

DOCTORAL DISSERTATIONS 236/2019

(C) 2019 Emma Salminen

ISBN 978-952-60-8884-6 (printed)

ISBN 978-952-60-8885-3 (pdf)

ISSN 1799-4934 (printed)

ISSN 1799-4942 (pdf)

http://urn.fi/URN:ISBN:978-952-60-8885-3

Unigrafia Oy

Helsinki 2019

Finland 
Author

Emma Salminen

Name of the doctoral dissertation

Consumers in the Circular Economy: Essays on Extending Product Lifecycles

\begin{tabular}{l}
\hline Publisher School of Business \\
Unit Department of Marketing \\
\hline Series Aalto University publication series DOCTORAL DISSERTATIONS 236/2019 \\
\hline Field of research Consumer Research \\
\hline Date of the defence 24 January 2020 \\
$\begin{array}{l}\text { Language English } \\
\square \text { Monograph }\end{array}$ Article dissertation \\
\hline
\end{tabular}

\section{Abstract}

This dissertation sheds light on how a better understanding of consumer practices during product use can help us make consumption more sustainable. The role of consumers in circular economy models has been underexplored and marginalized. The discussion on product circularity is often framed around production and design, where consumers are treated as passive users of circular offerings. Instead, this dissertation elaborates on how consumers can have active roles in the circular economy by extending product lifecycles through maintenance.

In this dissertation, I build on the cyclical view of consumption that looks at consumption through acquisition, usage, and disposal. The dissertation focuses on the usage phase of the cycle. To escape the traps of the previous attitude-behavior studies focusing on the individual consumer's attitudes and behavior, this dissertation draws from a more holistic view taking macro, meso, and micro perspectives into account. The research draws on practice theory and analyzes the different practice elements and their configurations. By taking a macro perspective, the findings of the dissertation elaborate on institutional regulations, market resources and social structures shaping practices during product use. Through a more micro and meso perspective, the findings bring new understanding to how consumers participate in lengthening product life spans and how they keep products part of their practices through product maintenance.

The dissertation is comprised of three interlinked essays that draw from a longitudinal ethnographic study exploring consumption practices through a sustainable perspective. The study context focuses on leisure boating in Finland, Sweden, Denmark, and Germany. The context of leisure boating around the Baltic Sea provided an excellent context to study sustainable consumption practices due to the extensive use of unsustainable, environmentally destructive boat hull paints during maintenance practices.

Keywords Circular Economy, Sustainable Consumption, Practice Theory

\begin{tabular}{lc}
\hline ISBN (printed) $978-952-60-8884-6$ & ISBN (pdf) $978-952-60-8885-3$ \\
\hline ISSN (printed) $1799-4934$ & ISSN (pdf) $1799-4942$ \\
\hline Location of publisher Helsinki & Location of printing Helsinki Year 2019 \\
\hline Pages 166 & urn http://urn.fi/URN:ISBN:978-952-60-8885-3 \\
\hline
\end{tabular}





\section{Acknowledgements}

No one writes their dissertation alone. This is even more obvious in the case of having an essay-based dissertation with co-authored essays which is based on an interdisciplinary and international research project. There are countless people to thank for the realization of this dissertation. I am truly thankful for all the comments, discussions, funding and especially the love and friendship.

First of all, I would like to thank my supervisor Henri Weijo without whom I would not have even thought of starting this PhD journey. Thank you for the discussion at Acti's Christmas party sometime in 2013, for letting me know of an interesting research project, and thank you for bringing me along. Thank you for the support and encouragement through the process and bringing me back on track when I have felt totally lost with my dissertation. I admire your passion for research and intelligence. Also, Diane Martin, altough no longer with Aalto, deserves acknowledgment for bringing me into the project and introducing me to the great CHANGE team.

I would like to thank Dr. Benjamin Hartmann and Dr. Andrea Prothero. I feel very honoured to have had them serve as the preliminary examiners of my dissertation and to have Dr. Hartmann serve as my opponent. Thank you for inspiring and challenging me. I very much appreciate your insightful comments. This work would not have been possible without the financial support of the BONUS CHANGE (changing antifouling practices for leisure boats in the Baltic Sea) project. To all the sailors and boat owners I got to meet and interview: thank you for sharing your fascinating stories from the sea. I would also like to thank my co-authors: Anu Harju and Bianca Koroschetz. I gratefully acknowledge the generous financial support from the Foundation of Helsinki School of Economics and Yrjö Uitto Foundation.

During my doctoral studies I had the priviledge to visit University of Melbourne as visiting researcher. Julie Ozanne deserves a special acknowledgment for hosting me and inspiring me to reflect my own orientations and the goods of academic work.

Thank you for my friends and colleagues at the Department of Marketing at the Aalto University School of Business. I want to express my gratitude to our department head Arto Lindblom and the previous head Tomas Falk for your support. I also wish to thank Eric Arnould who has supported and encouraged me and Ilona Mikkonen and Kristina Wittkowski for the honest talks and help. Thank you Eveliina Konttila, Pihla Steinberg and Eevi Huhtamaa for your patience and help with the administrative stuff. Finally, especially great thanks to 
the great bunch of current and past doctoral students with whom I have had the joy to share this journey with: Hedon Blakaj, Kushagra Bhatnagar, Alexei Gloukhovtsev, Juho-Petteri Huhtala, Mikko Hänninen, Hunter Jones, Olga Lavrusheva, Sonja Lätti, Maria Del Rio Olivares, Tatsiana Padhaiskaya, Laura Rosenberg, Usva Seregina, Jack S. Tillotson, and the rest.

Countless others have helped me through their support, by giving comments, having inspiring conversations and giving encouragement. I would not have borne the stress and ambiguity at times without my dear friends in Heimoneuvosto and Kangasalan plikat. Thank you for the support, the laughs and hugs. Also, my personal IT helpdesk Karri Tuominen deserves a special acknowledgment. Finally, thanks to my family, especially mom, without whom I would not have the passion for nature and the courage to pursue my dreams. Thank you Päivi, Iida and Andreas for the support and countless hours of babysitting. Ilkka, there are no words to thank you enough for your love and support. Thank you for being there throughout the process. My dearest Lilja, thank you for joy and playfulness and teaching what truly matters in life.

Helsinki, 10 December 2019

Emma Salminen 


\section{Contents}

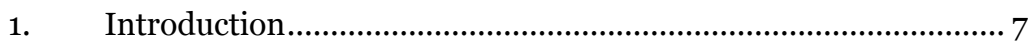

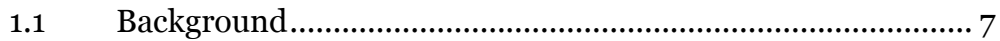

$1.2 \quad$ Research context................................................................... 9

1.3 Research questions and outline of the dissertation................ 10

$1.4 \quad$ Structure of the dissertation....................................................11

2. Theoretical background .................................................................13

$2.1 \quad$ Defining sustainability ….......................................................13

2.2 From linear to circular economy .......................................... 14

2.3 The role of consumption in sustainability ............................ 16

2.3.1 Problematics of the individualistic approach to sustainable consumption .................................................................................17

2.3.2 Holistic approaches to sustainable consumption .................. 19

2.3.3 Circular view of consumption .................................................21

2.3.4 Products usage - the missing part of circular consumption.22

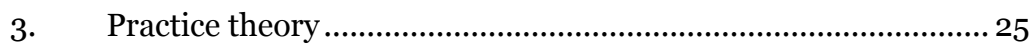

3.1 Practice theory in consumer research.................................... 26

3.2 Practice elements................................................................ 27

3.3 Practice theory in sustainable consumption ...........................28

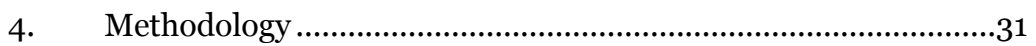

4.1 Ethnography as a method .....................................................31

$4.2 \quad$ Research methods and data .................................................... 33

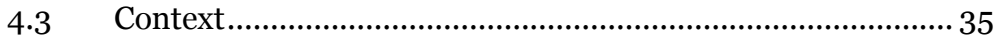

4.4 Context of context................................................................. 37

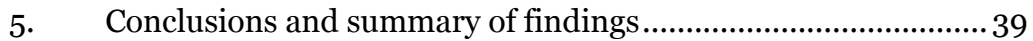

5.1 Essay I: More Than One Way to Float Your Boat: Product Use and Sustainability Impacts

5.2 Essay II: Experiencing Nature through Nordic Restrictions and Freedom 40 
5.3 Essay III: Maintenance Practices in Communal Consumption: An Ethnography of Baltic Sea Sailors 41

$5.4 \quad$ Limitations and future research avenues ............................. 43

References........................................................................................ 45

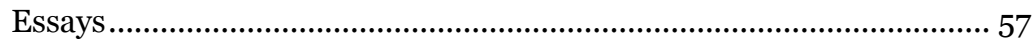




\section{List of Publications}

This doctoral dissertation consists of an introductory part and of the following three essays, which are referred to in the text by their numbers.

1. Martin, Diane M.; Harju, Anu; Salminen, Emma; Koroschetz, Bianca. 2019. More Than One Way to Float Your Boat: Product Use and Sustainability Impacts. Journal of Macromarketing. Volume 39, issue 1, pages 71-87. DOI: https://doi.org/10.1177\%2Fo276146718817600.

2. Salminen, Emma. 2019. Experiencing Nature through Nordic Restrictions and Freedom. In Nordic Consumer Culture. Palgrave Macmillan, Cham. Pages 147-168. DOI: https://doi.org/10.1007/978-3-030-04933-1_7.

3. Salminen, Emma; Weijo, Henri. Maintenance Practices in Communal Consumption: An Ethnography of Baltic Sea Sailors. Unpublished essay. 


\section{Introduction}

\subsection{Background}

People are using Earth's resources faster than they can replenish and polluting the Earth faster than it can recuperate (Meadows, Randers and Meadows 2004, p3). In the face of climate change, sustainability has become a burning question among politicians, industries and consumers. There is a pressing need to reduce the resource-throughput of products resulting from the throwaway culture of discarding things that are in good shape. A move away from the linear productuse-dispose model to a circular economy perspective is critical for preserving scarce natural resources (European Commission 2014; United Nations 2016). Circular economy emphasizes designing "closed loop" economic systems which reduce resource usage and waste (Kichherr, Reike and Hekker 2017). Yet, the role of consumers in the circular economy has been underexplored and underestimated (Camacho-Otero et al. 2018; Lofthouse and Prendeville 2017; 2018; Wastling et al, 2018). The discussion on product circularity is often framed around production and design (Selvefors et al. 2019). In such views, consumers are treated as passive users to whom the products ought to be designed so that they enable circular opportunities (see e.g. Selvefors et al. 2019). Yet, changes in consumption are equally important (Kirchherr et al. 2017, Selvefors et al. 2019).

The overall environmental impact of consumer behavior is of major concern for the current and future wellbeing of life. Hence, scholars have already been studying how to change consumer behavior most effectively towards more sustainable behavior (see McDonagh and Prothero 2014 for a review). Yet, decades of attitude-behavior gap studies have not resolved the problem of why consumers do not change their behavior towards more sustainable practices, even when they espouse "greener" values (Wilhite et al. 2000). Those studies view consumption choices as autonomous and isolated sets of actions and ignore contextual and systemic factors (Dolan 2002). My dissertation study aims to move away from the previous sustainable consumption discussion on the attitude-behavior gap, which sees unsustainable consumption resulting from the gap between individual consumers' attitudes and behavior (Heiskanen and Pantzar 1997; Vermeir and Verbeke 2006; Gupta and Ogden 2009). In 
contrast, I take a more holistic approach to studying sustainable consumption. My approach is similar to studies viewing consumer behavior as a product of shared, engrained habits, routines, rituals, and preferences situated in wider networks of prescribed cultural and social practices (Bartiaux 2008; Spaargaren 2002; Swidler 2001). Accordingly, social structures are then brought into the center of the analysis through practice theory (Shove et al. 2012).

Practice theory explores consumption through the ongoing routines, performances, materials, and teleoaffective engagements which structure and organize social life (Arsel and Bean 2012; Schatzki 2002; Swidler 2001). Practice theory considers consumption not as a practice itself, but as an element of nearly every practice (Warde 2005). The theory has become increasingly popular in consumer behavior and sustainable consumption studies, as it enables scholars to gain a holistic picture of consumption practices (Røpke 2009) or understand social change (Shove et al. 2012; Hand, Shove and Southernton 2005), for example. Most importantly, practice theory offers an avenue away from the attitude-behavior gap, as it does not focus on the individual, but on social practices (Welch and Warde 2015). The theory allows studies to explore how more sustainable management can be developed in ways that are consistent with consumers' current practice portfolios (Shove and Pantzar 2005; Røpke 2009; Spaargaren 2011).

With the practice theory perspective, this dissertation takes a circular approach to sustainable consumption. Circular economy (CE) literature has emphasized the importance of a cyclical view of consumption, where products form a closed-loop system from sourcing and production to use and disposal back to sourcing and production (Camacho-Otero et al. 2018; Selvefors et al. 2019). For example, the literature has emphasized the need to move from ownership and acquiring new possessions to engaging with for example repairing and returning products (Camacho-Otero et al. 2018). Following the CE ideology, recent sustainable consumption research encourages taking a full consumption cycle perspective of acquisition, usage and disposal (Prothero et al. 2011; Brosius, Fernandez and Cherrier 2013). Similar to CE, the full consumption cycle perspective aims to broaden the perspective of sustainable consumption literature. Here, the focus of the attention has traditionally been on product acquisition (e.g. Gupta and Ogden 2009; Assadourian 2010; Young et al. 2010; Moisander 2007; Vermeir and Verbeke 2006) and somewhat on disposal (e.g. Price, Arnould and Folkman Curasi 2000; Lastovicka and Fernandez 2005; Brosius et al. 2012). Yet, these studies have not taken practices of product use as the central focus. A notable exception are studies on collaborative consumption and sharing economy (e.g. Belk 2010; Bardhi and Eckhardt 2012a; 2012b; Hamari et al. 2013; Belk 2014), which take a fuller consumption view by focusing on non-ownership behavior rather than buying.

In this dissertation, I build on the cyclical view of consumption by focusing on the usage phase of the cycle (see figure 1). Yet, since all of the phases relate to each other through a cycle, I will touch upon acquisition and disposal as well. My dissertation builds a holistic view for sustainable consumption by taking macro, meso and micro perspectives into solving an environmental 
problem through sustainable consumption. The objective of the study is to deliver valuable knowledge and theories on product usage in the cyclical view of consumption, rather than to give complete answers to every situation. Previous studies have utilized the more holistic perspective in understanding sustainable consumption and taken a practice theory approach (e.g. Spaargaren 2011, Shove 2010). However, these studies have focused on product choice and post-choice disposal. Therefore, by taking a macro perspective, I explore how sustainable consumption can be reached by focusing on consumer practices during product use to understand consumers' role in the circular economy. This brings product maintenance into the center of the research where, through a more micro and meso perspective, I aim to understand why consumers engage in extending product lifecycles, keeping products part of their practices through maintenance. Further, taking a specific Nordic perspective permits understanding the context of context (Askegaard and Linnet 2011) and the socio-historic patterning of sustainable consumption practices. This leads to escaping the individualistic approach by considering how usage practice is situated in space, emphasizing the social structure of behavior (Spaargaren 2002).

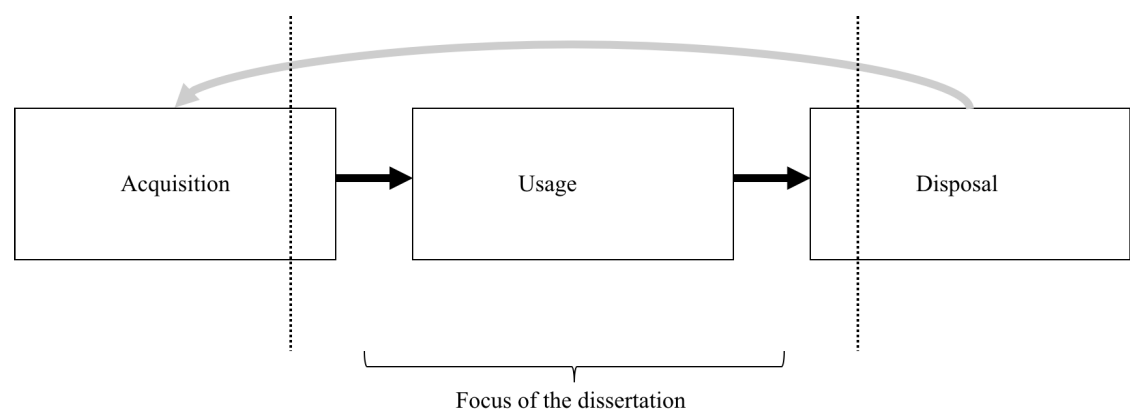

Figure 1. Focus of the dissertation in the full consumption cycle

\subsection{Research context}

The dissertation research has been part of a wider interdisciplinary EU project BONUS - Change (Changing antifouling practices for leisure boats in the Baltic Sea), taking place during 2014 to 2018 and focusing on improving the Baltic Sea ecosystem. All three essays are based on ethnographic data collected during the project and explore consumption practices through sustainable perspective. The study context focuses on leisure boating in Finland, Sweden, Denmark and Germany. My part of the research has played an important role in understanding maintenance and consumption practices in the context of leisure boating around the Baltic Sea in order to shift consumption practices towards more sustainable ones.

Currently, boaters extensively use unsustainable, environmentally destructive boat hull paints within their maintenance practices. These coats of paints are renewed frequently to fight biofouling, producing a steady toxic waste stream 
into the fragile Baltic Sea ecosystem (Yebra et al. 2004; Dahlström et al. 2014). Biofouling is a critical problem for boaters. The fouling organisms attached to the boat hull increase the boat weight, slow the boat and make maneuvering more difficult, not to mention aesthetic considerations (Yebra et al. 2004). The main active ingredients (biocides) preventing biofouling in antifouling paints are toxic heavy metals, i.e. copper and zinc. The use of antifouling paints continuously adds to the inflow and accumulation of biocides in the Baltic coastal ecosystem, which has lethal effects on marine organisms (Thouvenin et al. 2002). The context proves highly interesting, as leisure boaters and especially sailors are often nature-oriented, thus professing green attitude. However, these attitudes do not lead to more sustainable behavior. It thus amounts to yet another attitude-behavior gap within green consumption.

The context of leisure boating around the Baltic Sea is an interesting one in which to study how to make consumption practices more sustainable by focusing on product use. As the Baltic Sea is one of the largest brackish water environments in the world, toxins and emissions from around 80 million people in 14 countries make it a highly polluted area causing health issues (Eklund and Eklund 2014). The current maintenance practices of more than 3,5 million leisure boaters are destructive to the environment, especially since they influence the fragile archipelago areas of the Baltic Sea (Dahlström et. al, 2014). As such, the three interlinked essays in my dissertation take on a cultural perspective, studying the social importance and meaning of boating and connected maintenance practices as well as the cultural specialties of Nordic consumer culture. The socio-cultural significance of boating and boat maintenance can hinder environmentally sustainable innovation, especially because boat owners may be blind to their own habits. Also, boating has a strong cultural heritage in the Nordics and thus needs deeper understanding and influencing tactics to change the unsustainable consumption behavior. The results of the study are used by environmental organizations such as Keep the Archipelago Tidy, boat clubs, and boating associations, as well as the Ministry of the Environment and the Finnish Safety and Chemicals agency.

\subsection{Research questions and outline of the dissertation}

The dissertation is comprised of three interlinked essays, two of which are published in a peer reviewed journal and a book and one that is currently under review in a journal. The three essays contribute to answering the main research question of the dissertation, that is: How to reach sustainable consumption by focusing on consumer practices during product use? Even when previous circular economy and practice theory inspired sustainable consumption studies have looked at changing consumption behavior through practices, they have rarely focused on the product use category and especially maintenance. 
In the first essay, together with Diane Martin, Anu Harju and Bianca Koroschetz, I explore how consumer practices during product use results in a wide variance in overall environmental sustainability impacts. Employing the practice theory lens, the essay acknowledges how different practice elements shape the sustainability of a product. Our analysis of different configurations of practice elements resulted in four practices configurations of leisure boaters: The Proper Boater, the Opportunist, the Green Boater, and the Negotiator. The essay helped to further acknowledge how focusing on product use influences overall sustainable consumption.

In the second essay, I explore how Nordic consumers' nature experiences are orchestrated through an interplay of Nordic ideologies of nature with Nordic governmental apparatuses. This book chapter brought a more holistic approach to the sustainable consumption of product use by expanding the contextualization of the consumers' lived experiences to the structuring of the social system. The essay brought up that on one hand, Nordic everyman's rights and nature ideologies bring freedom for Nordic consumers to enter and experience nature equally. On the other hand, the Nordic states setting strict governmental rules promoting ideologies restrict nature experiences. The chapter studies Nordic sailor's nature experiences by focusing on both sailing as an experience as well as sailboat ownership and related maintenance.

In the third essay, together with Henri Weijo, I explore how and to what end consumers perform maintenance practices in communal consumption contexts where consumption objects require regular maintenance. This essay helps to understand why consumers would engage in product use practices such as maintenance. We take a communal perspective, as it further allows us to illustrate the communal aspects of maintenance, how tools and competences are shared, and how the community dictates the practice. Hence, the essay allows us to extend the understanding of product use practices from individual level to communal practices.

\subsection{Structure of the dissertation}

This dissertation comprises of two parts. The first part gives an overview of the theoretical background of my dissertations. The second part consists of the three essays. In the first part, I will first review literature on sustainability. The first chapter specifically focuses on explaining how and why the transition towards circularity is needed and how it has been previously studied. I then move to explaining the role of consumption in sustainability. The second chapter will go through the move from an individual to a more holistic approach in sustainable consumption. I will then explain what the circular view of consumption means and how product use is studied in previous research to show the missing parts. In the third chapter, I discuss practice theory in consumer research and 
sustainable consumption within previous research. In the fourth chapter, I introduce the methodological choice of ethnography and the research process briefly and elaborate on the fieldwork and analytical process. Finally, chapter five combines the findings of the three essays to form a holistic answer to the main research question of the dissertation. 


\section{Theoretical background}

In this part of the dissertation, I describe the basics of sustainability and circular economy. The purpose is to position my research in the wider theoretical and practical phenomenon of sustainability. Firstly, I define sustainability briefly. I then review how literature on sustainability has increasingly moved towards circular economy literature. Secondly, I will introduce the role of consumption in sustainability. I first discuss how sustainable consumption research has evolved from studying individual consumers into taking a more holistic approach. This then leads to explaining the circular view of consumption and the gap in product use in the current sustainable consumption literature.

\subsection{Defining sustainability}

It is now widely agreed upon among scholars, politicians and ordinary citizens that we are reaching the limits of the capacity of our planet. We are running out of critical resources (UNEP 2012) and many patterns of consumption are fundamentally unsustainable (Shove 2010; McDonagh and Prothero 2014). No matter which indicator we choose, humans have put increasingly more pressure on the earth (Chappells and Trentmann 2015). For example, after the eighteenth century, the rate of carbon dioxide emissions into the atmosphere has accelerated, global water use has increased, and the world's population has grown more than six-fold between 1700 and 2000 (Chappells and Trentman 2015). Due to these realizations, sustainability has become a megatrend (Lubin and Esty 2010). The sustainability literature is vast and largely studied, both in marketing, but even more so outside of marketing literature. Therefore, the sustainability discourse has multiple and contested voices (McDonagh and Prothero 2014).

The most commonly referenced definition of sustainability is from the Brundtland Commission Report: "the development that meets the needs of the present without compromising the ability of future generations to meet their needs (WCED 1987, p. 8). Sustainable development used to focus only on environmental and economic development (Moldan 2011). Yet, a well-known approach in sustainability is called the triple bottom line, which divides sustainability into three dimensions: environmental, economic and social (Elkington 1998). The 
approach emphasizes that in order for businesses to attain ultimate success, not only economic profit, but also people and the planet need to be taken into consideration (Norman et al. 2004; Colicchia et al. 2013). However, the approach has been criticized for not including a common unit of measure (Slaper et al. 2011). Whereas economic sustainability might be easy to report, measuring social capital has proven problematic (Slaper et al. 2011). Where the Brundtland Report made sustainable development the focus of global environmental policy, the UN Conference on Environment and Development in Rio de Janeiro in 1992 operationalized the report's approach (Chappells and Trentmann 2015). For example, this so-called Agenda 21 gave attention to material flows by calling for an assessment of environmental impacts through the full life cycle of products (United Nations 1993). Hence, more sustainability discussion has geared towards circular economy.

\subsection{From linear to circular economy}

Sustainability practitioners and scholars have increasingly become interested in the concept of circular economy as a way to operationalize the concept of sustainable development (Ghisellini et al. 2016; Murray, Skene and Haynes 2017), which is seen too vague for implementation (van der Brande et al. 2011). Here, circular economy is viewed as a condition for sustainability (Geissdoerfer et al. 2017). Traditionally, the economy has been based on linear systems, where resources are extracted and then transported to factories, where they are processed into goods, after which these goods are sold to consumers, who dispose of them after use. This process creates a pressing need for always extracting new natural resources and is thus highly unsustainable. Hence, a move away from the linear production models and consumption patterns into circular economy has received much attention from scholars trying to come up with ways to solve the adverse environmental impacts.

The concept of circular economy (CE) dates back to the 1960 s (e.g. Boulding 1966). Since then, CE has gained popularity among both practitioners and academics, especially within the past years (Kirchherr et al. 2017). Previous research has studied for example barriers to CE (Kirchherr et al. 2018), as well as product design and business strategies for CE (e.g. van der Berg and Bakker 2015; Bocken et al. 2016), such as extending product lifetimes (e.g. Bakker et al. 2014a; 2014b). CE arguably has benefits for sustainable development (Bocken, Ritala and Huotari 2017), especially regarding the reduction of environmental impact in supply chains and productions (Kirchherrer et al. 2017; Spring and Araujo 2017). Production, use, and disposal of products all contribute negatively to the environment (Clark 2007).

The growing interest to study and use the concept of CE has resulted in a diffusion of description of the concept (Kirchherr et al. 2017). Kirchherr and colleagues (2017, p. 229) composed a coherent definition, based on a 
thorough study on the definitions of the concept, that this dissertation will follow. They define $\mathrm{CE}$ as:

"an economic system that replaces the 'end-of-life' concept with reducing, alternatively reusing, recycling and recovering materials in production/distribution and consumption processes. It operates at the micro level (products, companies, consumers), meso level (eco-industrial parks) and macro level (city, region, nation and beyond), with the aim to accomplish sustainable development, thus simultaneously creating environmental quality, economic prosperity and social equity, to the benefit of current and future generations. ”

The definition provides a sense of hierarchy among the different activities, prioritizes reduction and reusing over recycling and recovering, and emphasizes the role of consumers and organizations as enablers (Kirchherr et al. 2017). Even when limited to focusing on consumers and organizations as the only actors (Camacho-Otero et al. 2018), it serves the purpose of this dissertation. This dissertation focuses especially on the micro perspective of the definition by shedding light on how consumers partake in the circular economy through reusing, recycling and reducing materials in consumption processes. In order to understand how to move towards a more circular economy, I will next explain the problematics of current use and design of products.

To support the transition from linear to circular economy, designers and researchers are looking for ways to circulate materials and fight against short product lifecycles in order to decrease the negative environmental causes of the throwaway mentality (Cooper 2004; 2005). We live in a throwaway culture, where the lifetime of products is short and disposing of fully functioning products is common (Cooper 2016). It is obviously a drain to environmental resources to discard things when they are still in good shape. The throwaway culture is also shifting the role of objects as their role in consumers' lives and culture is diluting (Verbeek and Kockelkoren 1998, p. 28). Thus, the concept of planned obsolescence and especially how to move away from it has gained interest among scholars and practitioners.

The issue of planned obsolescence, of designing a product with a limited usage time so that it becomes obsolete after a while, has been widely studied in the production literature (e.g. Fishman, Gandal and Shy 1993; Guiltinan 2009; Bakker et al. 2014a). Packard (1960) popularized the concept to deliberate the shortening of product lifecycles. At the time, planned obsolescence was mainly discussed in the context of diluting the quality of products (Cooper 2004). Only in the 1990 s was obsolescence discussed from the sustainability perspective (Cooper 2004). There are three kinds of obsolescence: technological, common to electronic goods; economic, due to new more energy- or cost-efficient substitutes entering the market; and psychological, where the consumer prefers fashionable or more stylish substitutes (Cooper 2004). The declining lifespan of products may lead to detrimental environmental consequences, especially from 
the production perspective (Bakker et al. 2014). As this shows, the discussion on circular economy has been focusing on mostly production and design.

Yet, consumers too partake in the circular economy. The research of circular economy is often framed around production or business models (Rizos, Tuokko and Behrens 2017; Selvefors et al. 2019). Even when the definition and previous research acknowledges that consumers' involvement is necessary to the functioning of circular economy, there is very little literature taking the consumer's perspective and studying consumer responses to the circular offerings (Mugge 2017; Rizos et al. 2017; Camacho-Otero et al. 2018). Yet, whether products designed following the circular principles and prolonged lifetimes will actually be used and taken into use depends on the people using the products (Selvefors et al. 2019). Previous research has noted that user acceptance can be a significant factor hindering the implementations of circular business models (Rizos et al. 2016; Kirchherr et al. 2017). Similarly, Scott and Weaver (2014) suggest that consumers should be encouraged to be innovative with their possessions, as that would more likely lead to a higher likelihood of repair. Hence, previous research calls for more focus on consumers and consumer acceptance (Kirccherr et al. 2017; Camacho-Otero et al. 2018) that this dissertation aims to respond to. This dissertation builds on the previous sustainability and circular economy research by bringing the consumer's perspective through focusing on product extensions, especially maintenance. Hence, I will move into discussing the role of consumers in the move towards a more sustainable future.

\subsection{The role of consumption in sustainability}

Unsustainable social and economic behavior is claimed to be one of the main reasons for environmental degradation (Heiskanen and Pantzar 1997; Cohen 2006). Hence, scholars have been increasingly interested in how to change consumers' behavior into more sustainable practices (Cohen 2006). Yet, sustainability is not a new phenomenon. People have had to think about the impacts of their acts on the future in all periods in history. Even agrarian communities had to consider how to manage and ensure the future availability of for example water, forests and crops (Chappells and Trentmann 2015). Still, one of the main reasons for environmental problems is overconsuming natural recourses (UNEP 2012). The Agenda 21 set forth a framework for managing excessive demands and unsustainable lifestyles and devoted a chapter to "Changing Consumption Patterns" (United Nations 1993). Since then, the general consensus has been that sustainable consumption is not only important, but also necessary for the future (Nielsen 2011).

Research on sustainable consumption aims to understand and promote consumption behavior leading to sustainable development (Reich and Thøgersen 2015). Sustainable consumption is often used synonymously with ecological, green, or ethical behavior (Verplanken and Roy 2015). Similar to the broader concept of sustainability, the most common definition follows the 
World Commission on Environment and Development, resulting from the work on sustainable development, defined as meeting "the needs of the present without compromising the ability of future generations to meet their own needs" (WCED 1987, p. 8). Hence, sustainable consumption contributes to the survival of future generations (Kilbourne et al. 1997) and takes into account environmental, economic and social sustainability (Heiskanen and Pantzar 1997). Also, sustainable consumption is a decision-making process taking into consideration consumers' social responsibility as well as their individual needs and wants (Vermeir and Verbeke 2006).

Yet, the definition leaves out the question of what forms of consumption can be considered sustainable. Quite obviously, not all type of environmental behavior matters equally (Stern 2000). This is where methods measuring the impacts of consumption and production, such as life cycle assessment (LCA), come into play. The United Nations put forward a life cycle assessment method that aims at quantifying the overall environmental impacts of consumption activities (UNO 2002). The method is usually used in natural sciences and describes impacts associated with product systems and services during the production, distribution, use and disposal of a product (ISO.14040 1997). The advantage of LCA is indeed its holistic and versatile approach to sustainability which allows analyzing complex processes (Hertwich 2005). However, LCA has been little used in the context of sustainable consumption, as the focus has been more on the sustainable production side (Hertwich 2005).

Next, I will firstly explain how the focus on sustainable consumption has shifted from only looking at individual values and attitudes at the micro level to a more holistic macro focus on sustainable consumption. Then I will explain the circular view on sustainable consumption and especially explain how product use has been neglected in previous sustainable consumption research.

\subsubsection{Problematics of the individualistic approach to sustainable con- sumption}

The early work of sustainable consumption research was interested in individual consumer behavior and concerns. This research stream has still been continuing (see McDonagh and Prothero 2014 for a review). These studies focused on categorization of the green consumer to determine their value as a marketing segment (see Kilbourne and Beckmann 1998 for a review). A majority of the studies on green consumers sought to understand whether and how environmental concerns lead to environmental behavior (Kilbourne and Beckmann 1998; McDonagh and Prothero 2014).

Individualistic approaches to sustainable consumption target individual consumers for reaching a sustainable target (Shove et al. 2012). They focus on the micro level of sustainable consumption, such as individual attitudes, emotions, beliefs, norms and values for promoting sustainable consumption (Stern 2000). Since the Agenda 21 was set forth, many attempts have been made to change consumers' attitudes through sharing knowledge on the effects 
of unsustainable consumption (Jackson 2005). Also, in marketing, more studies previously focused on the micro level of sustainable consumption. Similarly, most activist and policy initiatives have focused on influencing consumer choices through transforming personal attitudes and values into more sustainable ones (Holt 2012). Hence, policy makers prefer information and awareness campaigns which persuade consumers to change their individual behavior to be more sustainable (Keller et al. 2014).

Many of these previous sustainable consumption studies have approached behavior as a linear and rational process (Hargreaves 2011). They are derived from Ajzen's (1991) "theory of planned behavior" (Hargreaves 2011) or expectancy-value theory, where the basic tenet is that people behave in order to maximize their expected benefits (Jackson 2005; Phipps et al. 2012). Following this logic, in order to change consumers' behavior to be more sustainable, we would need to change their attitudes into pro-environmental ones. These proenvironmental attitudes would then lead to more sustainable consumption. However, the studies consistently found that even when consumers are concerned about the environment, i.e. they have a sustainable attitude; they are not behaving accordingly, i.e. their actions are still unsustainable (e.g. Vermeir and Verbeke 2006; Gupta and Ogden 2009). This inconsistency between attitudes and behavior is referred to as the attitude-behavior gap (Young and Middlemiss 2012). As a personal example, even though I have spent the last four years reading and learning about sustainability and I think I have a highly sustainable attitude, not all my acts are sustainable. For example, I routinely fly long-distance to attend conferences. And even when the titles of the conferences at times have "sustainability" in them, it still does not make my flying for a few days' trip any more sustainable. Whereas this logic might work in other contexts, sustainable behavior is somewhat special, as it includes not only the benefits for the individual, but also for the environment and/or others (Phipps et al. 2012). Hence, the results of the attempts focusing on individualistic approaches remain insufficient (McMeekin and Southerton 2012; Carrington, Neville, and Whitwell 2014).

The results from attitude-behavior studies have even been contradictory at times (Kilbourne and Beckmann 1998). For example, Follows and Jobber (2000) showed a hierarchical relationship from values, to attitudes and to purchase. More recently, Giesler and Veresiu (2014) introduced a viewpoint of consumer responsibilization, requiring the active creation of consumers as moral subjects. Specifically, following the neoliberal logic, they argue that the responsibility ought to be assigned to the individuals with freedom to choose, and supported by moral guidelines. Giesler and Veresiu (2014) suggest that consumers should not be treated as passive citizens or victims, but rather we should let them decide for themselves and empower them to take actions. Yet, recent studies have questioned the ethical consumer ethos (e.g. Chatzidakis, Maclaran, and Bradshaw 2012; Bertilsson 2005; Devinney, Auger, and Eckhardt 2010). In fact, Devinney et al. (2010) argue that the ethical consumer is a myth, firstly as it represents a fictional role model: such a consumer simply does not exist. Secondly, they argue that the ethical consumer is an idealization contesting the 
existing flawed consumer behavior which leans on guilt. Thirdly, even when the ethical consumer represents a role model, they say that the morality of the model itself is disputable. Additionally, the green consumer ethos has proven problematic, as while environmentally conscious consumers may buy products labeled as sustainable, they still consume, only differently (Connolly and Prother 2003).

Furthermore, the attitude-behavior studies often suggest moving away from capitalistic values such as materialism and consumerism as a solution for reaching a more sustainable future (Holt 2012). Materiality and consumption are often discussed in a rather negative tone in sustainability literature. Sustainability research often explores materialism in the context of consumerism (Assadourian 2010; Wijetunga 2019). Consumerism points to the expansion of "new, modish, faddish or fashionable, always improved and improving" material goods (Slater 1997, p. 10). Some researchers even argue that the only possible solution to move away from unsustainable consumption behavior is to move completely away from consumerism - the less we consume the less we need to produce, and the less harm is caused to the environment (e.g. Jackson 2005).

Yet, recent studies argue that attitude-behavior studies are being too concentrated in isolated behavioral items (Shove 2010; Shove et al. 2012). Instead, the more socially oriented studies have aimed to understand the social structures of sustainable consumption (Spaargaaren 2003). They consider consumer behavior to be historically developed by cultural and social interdependencies (Dolan 2002) which I will present next.

\subsubsection{Holistic approaches to sustainable consumption}

The more holistic approach studies the social context in which consumption is embedded (Spaargaren 2003; Welch 2017) and considers the role of cultural aspects in influencing consumer behavior. These studies see consumers rather as consumer-citizens than as self-interested consumers (Prothero et al. 2011). Additionally, the macro level of sustainability focuses on the market level, such as third-party labeling schemes (Thøgersen 2005) and market level ideologies (Holt 2012).

Cultural studies reject the autonomous view of behavior that the attitude-behavior studies take, and relate sustainable consumption to cultural and social practices (Dolan 2002; Connolly and Prothero 2003). They argue that a thorough study needs to consider behavioral practices situated in time and space practices that consumers share with others - thus emphasizing the social structure of behavior (Spaargaren 2002). Hence, the more social view not only sees consumers consuming products and services responding to basic needs, but sees those needs interrelated into a social and cultural context (Dolan 2002). These studies show that social structures, including macro structures like government and markets, as well as meso structures such as communities, should be taken into consideration. 
Sustainable consumption studies have emphasized the importance of communities in providing opportunities for sustainable practices (Moraes et al. 2012; Sahakian and Wilhite 2013). According to Holt (2012), whether a market has the potential to become sustainable depends on social movements and subcultures within the market. Jackson (2005) further explains that behavioral change should take place at the social level, since consumers are constantly influenced by social norms. This includes creating an ethical space bound to communities' norms and meanings in order to facilitate and shape images for sustainable consumption (Moraes et al. 2012).

Where the studies taking the more individualistic approach often blame consumerism and suggest moving away from the capitalistic values (Holt 2012), the more holistic approach takes a broader perspective on consumerism and consumption (Cherrier 2009). To move away completely from the consumeristic society would be not only too slow, but also very difficult (Holt 2012). Some studies have even indicated that in some cases, anti-consumption movements, such as voluntary simplicity, where consumers aim to minimize their consumption, actually result in higher uses of resources and even consuming more products (Craig-Lees and Hill 2002). To move away from consumerism would be difficult or even impossible, since consumption and product ownership provide comfort, help in the construction of one's self and in communicating it to others, and also satisfy physical and emotional needs (Cherrier and Murray 2007). Arnould (2007) also argues that consumerism is a powerful tool for consumers to influence political actions in the marketplace - to have agency in the marketplace. In addition, Holt (2012) notes that consumerism is dominating the overall society and is impossible to move away from quickly. It is not a distant or autonomous set of generic values, and it is not the only cause of unsustainable consumption. Therefore, rather than demanding a move away entirely from consumerism, we should understand market institutions and consumer practices (Holt 2012).

Hence, sustainable consumption should focus on understanding the current consumer culture and the role of materials embedded into it. Cultural studies of consumption have been exploring possessions in terms of identity construction and extended self (Arnould and Thompson 2005; Tian and Belk 2005). The studies claim that consumption can help in defining self when consumers choose products according to their self-image (Schau and Gilly 2003). Consumption is a route for understanding consumers' practices, thoughts and needs. Since it is not a fixed thing, personal identity can be formed or reformed by consumption (Belk 1988). Numerous consumption possessions reflect identity (Ahuvia 2005). Material objects which are owned by someone become cues for defining how the person is perceived by themselves and by others (Tian and Belk 2005). Belk (1988) sees consumers as possessing an inner core self which is expanded to items that become part of the extended self. The extended self can be experienced through a concrete set of things, people or places (Belk 1988). Consumers honor long-term commitments, and thus their lack challenges the sacred possessions of individuals (Tian and Belk 2005). 
All these arguments point to the direction that rather than fighting against consumerism, the focus should be directed towards making the current culture more functional through enhancing product and material circulation. Hence, there has been a recent shift to take the practice theory perspective in sustainable consumption studies (e.g. Røpke 2009; Magaudda, 2011; Spaargaren 2011; Shove et al 2012) which I will present in part 3. Yet, studies taking a circular view of consumption have noted that even the holistic approach does not consider the full life cycle of products enough. Consequently, the next subchapter will discuss the circular view of sustainable consumption to bridge this gap.

\subsubsection{Circular view of consumption}

Many of the previous sustainable consumption studies have approached consumption as a linear and rational process (Hargreaves 2011) starting from acquisition, through to use, and ending with disposition (Prothero et al. 2011). Traditionally, sustainable consumption has been divided into three R's: reduce, reuse and recycle. In sustainable consumption, the focus of the attention has traditionally been on product acquisition and reducing (Gupta and Ogden 2009; Assadourian 2010; Young et al. 2010; Moisander 2007; Vermeir and Verbeke 2006). Where traditionally marketers are interested in how to get consumers to buy more, sustainable consumption focus has directed attention towards less consumption (Jackson 2011). Hence, sustainable consumption studies focusing on the reducing category have distinctively discussed overconsumption and consumerism, and consumer movements and anti-consumption (e.g. Kozinets and Handelman 2004; Iyer and Muncy 2009; Cherrier 2009; 2010; Cherrier et al. 2011) such as brand avoidance (Lee, Motion and Conroy 2009), boycotting (e.g. Klein, Smith and John 2004), consumer resistance (e.g. Mikkonen and Bajde 2013), consumer movements and activism (e.g. Kozinets and Handelman 2004), and voluntary simplicity (e.g. Huneke 2005; Alexander and Ussher 2012). On the other hand, Jacoby, Berning and Dietvorst noted already in 1977 that more attention should be paid to product disposition. Since then, scholars have been increasingly interested in the recycling category studies focusing on product disposal and waste management (e.g. Brosius et al. 2012; Price et al. 2000; Kang and Schoenung 2005; Lastovicka and Fernandez 2005; Bulkeley and Gregson 2009; Wang et al. 2011; Hukkanen et al. 2013; YläMella et al. 2015; Benton 2015). However, Lee, Dewhirts and Cherrier (2018) still call upon more research on the end stage of consumption, especially on reuse, repurposing, maintenance and circulation.

Recent research on sustainable consumption (Prothero et al. 2011; Brosius et al. 2012) argues that consumer researchers should view consumption as a full consumption cycle of acquisition, usage and disposal. The perspective emphasizes the cyclical view of consumption where products are moving from acquired, consumed and disposed back to acquired, instead of the previous focus on consumption as a linear process which ends when the product is disposed of (Brosius et al. 2012). Hence, I argue that there is a clear synergy between 
circular economy and full consumption cycle literature. Both literatures use the same model ranging from acquired, used and disposed back to acquired (see e.g. Brosius et al. 2012, Selvefors et al. 2019). Circular consumption is a closed-loop system where materials are in a constant cycle, and in which materials are considered resources rather than recycled and considered waste (Scott and Weaver 2018). Hence, following the calls on taking a more cyclical view into consumption (Prothero et al. 2011; Brosius et al. 2012), the next subchapter will explain the gap on use and especially on maintenance in the consumption cycle.

\subsubsection{Products usage - the missing part of circular consumption}

Consumers take part in a circular economy mostly through the usage phase of the consumption cycle. Lengthening product life spans serves as an important avenue for facilitating sustainable consumption (Cooper 2005). Encouraging consumers to hold on to their possessions longer and to delay new acquisitions would decrease the overall material throughput in provision systems and further dilute the effects of throwaway culture (Cooper 2005). Yet, only a few studies focus on the usage phase. The rare studies where the usage phase has been taken into account emphasize that sustainable consumption should also aim at decreasing waste, expanding product life spans and keeping materials in circulation (Scott and Weaver 2018; Selvefors et al. 2019). The usage phase includes product life-extensions, such as the reuse of products, product maintenance, and product sharing, which all play important roles in enhancing sustainable consumption (Prothero et al. 2011). Therefore, if we want to understand consumers in the circular economy, we need to understand how and why they would engage in the usage practices both personally and communally.

Previous studies on circular economy which pay attention to the usage phase have mainly focused on the production and business model perspectives. For example, studies taking the LCA perspectives (e.g. Hertwich 2005) and user perspectives on product circularity in design processes (e.g. Selvefors et al. 2018) provide some information on the environmental impact of product use. For example, as the LCA studies measure all impacts related to product systems and services, they also provide some limited information about the environmental impact of product use (Hetwich 2005). Yet, LCA has been very little used in studying sustainable consumption, as it mainly provides information which consumers may not even know how to use (Hertwich 2005). Similarly, the designer-focused circular economy studies have looked at the design processes that enable the preconditions for circular product use (Bakker et al. 2014; Selvefor et al. 2018). For example, Selvefors et al. (2019) take consumption and product use as the point of departure and explore product exchange - more specifically, how products are circulated from user to user. Yet, they too take a designer perspective, leaving the consumer's role to be the use of whatever is designed in the proper manner. Hence, both the LCA approach and the circular economy literature have mainly treated consumers as passive recipients who do not take an active role in enhancing cyclical consumption. Therefore, more 
research on product circularity framed with the consumer taking active center stage is needed.

Similarly, some consumer research studies focusing on reuse have started to bring some understanding to product use. These studies illustrate the importance of understanding consumers as active agents in extending product lifecycles. Yet, the reuse category has received less attention within sustainable consumption literature (Scott and Weaver 2018). The lone exceptions are studies such as research studying how acquiring other people's trash creates a cyclical consumption model (Brosius et al. 2013) and a study on repair (Scott and Weaver 2014). Scott and Weaver (2018) for example studied repurposing, the act of assembling an object to a new purpose, to extend the product life cycle. They acknowledge that repurposing increases the attachment to the product, which might then lead to increasing the product life span. Additionally, they suggest that reuse should be considered a creative and productive activity rather than a sacrifice made for the sake of the environment. Yet, these studies leave out the maintenance perspective in connection to product circularity.

I will discuss maintenance in more depth in essay 3 and focus here on the sustainability benefits of maintenance. As Prothero et al. (2011) note, product maintenance influences product life and replacement by extending the product lifecycle and enhancing recyclability. Product life spans have decreased over the last decades (Kostecki 1998). Maintenance helps consumers prevent future repair costs by preserving or even upgrading their possessions to desirable levels of practical performativity (Takata et al. 2004). Regardless of these benefits, there is very little literature on how consumers are engaged or could be engaged in the usage stage of the product life cycle through maintenance and repair. Also, public policy relating to the reduction of resources often focuses on manufacturing processes and how to make them more environmentally friendly (Brosius et al. 2013).

More recently, explorations on innovative business models advocating access instead of ownership, such as collaborative consumption or sharing economy (e.g Bardhi and Eckhardt 2012; Belk 2014; Hamari et al. 2016), have further helped to expand the discussion of circularity and the role of the consumer. Collaborative consumption and sharing economy discussions point to the usage phase of the full consumption cycle. These innovative business models are based on sharing and accessing goods and services through community-based online services. From a sustainability perspective, increase in sharing could decrease the need for acquiring new products by moving away from individual consumption modes and thus overconsumption (Binninger, Ourahmoune and Robert 2015). Sharing and collaborative consumption provide consumers with a way to limit their product ownership by using products without owning them through using someone else's possessions (Belk 2009). However, I argue that also the sharing economy and collaborative consumption discussion lacks an important maintenance perspective, which would bring interesting new avenues for moving towards circularity and sharing. For example, when consumers rent or borrow products instead of owning them, companies can better control the usage and repair of their products. This should incentivize 
the companies to extend their product lifecycles through planned maintenance and repair procedures (Belk 2017; Becker-Leifhold 2018). Additionally, I argue that the need for maintenance may become even more extensive when moving towards sharing or circular economy, where the products circulated and shared need to be kept in good condition. There, the conditions of products become their key exchange value.

This dissertation studies product use through a practice theory perspective. The perspective makes it possible to take a holistic view of sustainable consumption and escape the attitude-behavior division. The next chapter will elaborate more on practice theory and how it helps in studying sustainable consumption practice through product use. 


\section{Practice theory}

Practice theory is not a unified theory, but encompasses multiple approaches that vary in scope and emphasis. Yet, all the theorists share the common thread of social life as a "nexus of practice", where different people's actions form a whole, thus sharing the assumption of social beings situated in practices (Schatzki 2012). The principal point for practice theorists is avoiding considering behavior an outcome of personal behavior choice or preference, and instead considering practices carrying both individualistic behavior and structures (Schatzki 2005). Practice theory derives from the philosophic background of Heidegger and Wittgenstein and has social science roots in Bordieu, Giddens and Foucault, called the first generation of practice theory (Schatzki et al. 2001; Halkier and Jensen 2011). Schatzki (1996, 2002) and Reckwitz (2002) have further developed their insights of the theory.

The first generation of practice theories focused only on human actors (Spaargaren 2011). The later generations regarded nonhuman entities equally important for the production of social practices (Schatzki 2002). The role of materiality is inspired by Latour's (2005) actor-network theory (Shove et al. 2012). This second wave of practice theories argues that interest in materiality enriches the theory by further allowing movement beyond the individual actor as a primary agent (Shove et al. 2012). What can be described as the third wave is comprised of studies which apply the theories empirically (e.g. Halkier and Jensen 2011; Halkier et al. 2011; Sahakian and Wilhite 2014).

Practice theory builds on flat ontology (Schatzki 2011), meaning that it is not hierarchical but relational. Practices are interlinked through bundles forming constellations and a large plenum of practice arrangements (Schatzki 2014). The flat ontology also helps explain the role of individuals. Individuals are decentralized, as they are considered as carriers of multiple practices (Keller et al. 2016). Yet practice theorists do not consider practitioners as dupes, but rather as active doers (Warde 2005). Reckwitz (2002 p.250) summarizes practices well as:

"a routinized way in which bodies are moved, objects are handled, subjects are treated, things are described, and the world is understood. To say that practices are 'social practices' is indeed a tautology: A practice is social, as it is a 'type' of behaving and understanding that appears at different locales and at different points of time and is carried out by different body/minds." 
Hence, the practice-theoretical approach places the practice as the unit of analysis (Giddens 1984; Reckwitz 2002). This allows for providing a "general and abstract account" (Schatzki 2001, p. 4) of the phenomenon under study.

Practices can be divided into practice-as-entity and practice-asperformance (Schatzki 1996; Warde 2005; Shove et al. 2012). Practice-as-entity refers to "a temporally unfolding and spatially dispersed nexus of doings and sayings" (Schatzki 1996, p. 89). Practice-as-performance can be defined as performance of the practice that "actualizes and sustains practices in the sense of nexuses” (Schatzki 1996, p. 90). Hence, practice-as-performance refers to an individual performance - a unique enactment of a practice (Hui 2017). In contrast, the practice-as-entity requires recurrent performances of a practice, as practices will disappear if they are not performed (Shove and Pantzar 2005).

\subsection{Practice theory in consumer research}

Practice theory is a relatively new theory in consumer behavior studies (Røpke 2009). The theoretical understanding rests on the assumption that markets, and hence consumption, are socially constructed phenomena (Holt 2012; Schatzki 2002; Shove and Pantzar 2005). Recent works have applied practice theory in studies of brand communities (Schau, Muñiz and Arnould 2009), proenvironmental behavior change (Hargreaves 2011), materiality (Magaudda 2011), taste regimes (Arsel and Bean 2013), temporal experiences (Woermann and Rokka 2015) and disrupted routines (Phipps and Ozanne 2017), to name a few. People are driven and motivated by practices and hence practices steer behavior (Warde 2005).

According to practice theory, consumption is not seen as practice itself, but it is almost always a moment in nearly every practice (Warde 2005). Practices also create wants and thus steer consumption behavior (Warde 2005). The theory explores consumption through the ongoing routines, engagements and performances of social life (Arsel and Bean 2012). Hence, due to the flat ontology, practice theory has become increasingly popular in consumer behavior studies as it enables movement away from isolated, contextual variables into a more holistic understanding of practices, and movement away from the actor-structure discussion (Warde 2005; Røpke 2009; Halkier et al.2011).

Most importantly, practice theory enables achieving a non-individualistic perspective on consumption (e.g. Hargreaves 2011). It enables focusing on social processes, as the central tenet is that the social is located in a nexus of practices, arrangements of human and nonhuman actors where social action as organized activity both transpires in and is understood in context (Schatzki 2002). Additionally, the theory allows looking at practice configurations as a whole, without demanding a separation between macro and micro perspectives. Practice theory hence puts more emphasis on doings, materiality, and embodied practical competences over the traditional research foci of consumer decision-making, 
symbolism, and intentional or expressive presentation of the self (Schatzki 2002; Warde 2005; Thomas and Epp 2019).

\subsection{Practice elements}

Practices are usually broken down into conceptualizations of different and interdependent elements. Schatzki (1996 p. 89) was first to introduce a conceptualization of elements being understandings, rules, and teleoaffective structure. In his later work, he split the understandings into practical understandings, which relate to Bordieu's habitus that refer to knowing what to do or say in a given situation, and general understandings, which relate to belief and meanings (Schatzki 2002, p. 77-82). Reckwitz (2002) introduced more elements such as the body, the mind, things and their use, know-how, states of emotions and knowledge. Later, Warde (2005) offered his own threefold model consisting of products, understanding and engagements.

In this dissertation, I follow Shove's and Pantzar's (2005) well-known understanding of practices as construction of meanings, competences and materials. Although not identical, there is some overlap between the analytical categories of meaning and Schatzki's (2002) general understandings. There is also overlap between the categories of competence and practical understandings. This tripartite terminology allows a clear distinction of the elements and enables focusing on their interconnection. The elements are interconnected and the linkages between them performed regularly and repeatedly (Shove et al. 2012). Thus, practices consist of both doings and sayings - both practical activity as well as its representations (Warde 2005) - and require performance for their existence (Warde 2005; Shove et al. 2012).

Materiality The material aspect encompasses objects, infrastructures, technology, tools, hardware and the body (Hand, Shove and Southerton 2005). Almost all practices include consuming materials and using them (Reckwitz 2002). Schatzki (2002) emphasizes the role of materials in shaping the connections in making a practice an entity. Warde (2005, p.131) continues by outlining that "consumption occurs as items are appropriated in the course of engaging in particular practices and that being a competent practitioner requires appropriation of the requisite services, possession of appropriate tools, and devotion of a suitable level of attention to the conduct of the practice". Shove and colleagues (2012) then further materialized practice theories using the term 'things'.

Meaning Meanings are socially shared ideas associated with the practice giving meaning to it (Shove et al. 2012). Schatzki (2002, p.80) uses the term teleoaffective structure to illustrate "a range of acceptable or correct ends, acceptable or correct tasks to carry out for these ends, acceptable or correct beliefs (etc.) given which specific tasks are carried out for the sake of these ends, and even 
acceptable or correct emotion out of which to do so" thus bringing the sociality into the practice. His view highlights how the right thing to do is different from what is rational to do (Schatzki 1987, p.120). Yet, meaning represents the social and symbolic significance of performing the practice (Shove et al. 2012, p. 23).

Competences Shove et al. (2012) combine all kinds of understanding and practical knowledge into an element of competence. Competence is thus a bundle of practical knowledge, forms of understanding and skills. Theories of practice often emphasize that performance in practice is usually not conscious (e.g. Warde 2005). A competent practitioner does what makes sense to oneself and draws on past meaning, rules and futures goals (Schatzki 2002). Competence consists of certain emotions in certain moments and know-how on how to behave in the practice (Reckwitz 2002). The practices hold a specific type of knowledge, understanding the world and having the required know-how, wanting and feeling in a specific way (Reckwitz 2002). Moreover, competence does not refer to only human doing but is also embodied in things (Watson and Shove 2008). The body is what brings practices into action, as individuals are carriers of practices performing practices constantly (Reckwitz 2002). Following Reckwitz (2002), bodies are not just instruments, but practices are "routinized bodily performances".

\subsection{Practice theory in sustainable consumption}

The question regarding practice theory in terms of sustainable consumption is how practice theory could inform the change towards more sustainable consumption. Or, how is unsustainable consumption embedded in consumer practices? As mentioned, the bulk of sustainable consumption studies have taken the individualistic approach, yet the contemporary consumption perspective acknowledges the importance of examining the social structures behind consumption (Spaargaren 2003; Welch 2017). Here, the practice theory perspective is especially useful as it moves away from analyzing individual behavior into analyzing social practices (Warde 2005; Røpke 2009). Hence, practice theory offers a way out of the attitude-behavior gap and its problematics (Welch and Warde 2015).

Research has increasingly used practice theory to study sustainable consumption, for example in studying showering to understand the environmental consequences of resource-intensive practices (Hand et al. 2005), energy practices to illustrate the link between technology and behavior (Wilhite 2008), everyday life and domestic practices to emphasize how most practices are performed with little consideration to the environment and how the focus should therefore be on collective efforts in sustainable change (Røpke 2009), pro-environmental behavior change to explore behavior change above individual's attitudes (Hargreaves 2011), cycling to understand why some practices are not available for consumers (Spotswood et al. 2015) and food consumption to recognize the 
agentive aspects of a practice (Sahakian and Wilhite 2013). However, none of these have looked at maintenance or extending product lifecycles. Previous studies have shown how practice theory is useful in the sustainable consumption context as it views consumers as not purely rational nor unconscious, but rather as agents bounded in sociocultural environments (e.g. see Shove and Pantzar 2005; Røpke 2009; Spaargaren 2011; Halkier et al. 2011). Spaargaren (2011) summarized well the common reasons for using practice theory in understanding unsustainable consumption as: 1) the role and responsibilities of the citizen consumer can be specified; 2) it gives an overview of the contribution of materials; and 3) the cultural framing of practice theory permits viewing the social construction of consumer behavior.

A recent stream of sustainable consumption studies taking the practice theory perspective argue that a main challenge in changing everyday consumption is that it is comprised of routines which are not actively reflected upon (Jaeger-Erben, Rückert-John and Schäfer 2015). The routinized habits are embedded in social and material context (Shove and Warde 2002, Jaeger-Erben et al. 2015). Practice theory allows focusing on the emergent nature of practices and thus behavior change (Hargreaves 2011; Halkier et al. 2011). Hence, a central question for sustainable consumption from the practice theory perspective is how to change habits (Sahakian and Wilhite 2013). The elemental nature of practices presents how practices evolve as the elements are linked and unlinked. Hence, a change into more sustainable consumption requires change in any of the three practice elements (Sahakian and Wilhite 2013). Practices change when the linkages or elements change. To create more sustainable practices, these linkages must be broken before the old practices can be replaced (Shove et al. 2012). The ways in which the different practice elements configure consumption practice and the dynamics between them all have transformational potential to sustainable consumption (Magaudda 2011; Shove et al. 2012). This is especially since practices are constantly changing and remade (Shove 2003; Hand et al. 2005).

This dissertation follows Røpke (2009) in linking environment and practices with material components such as products, infrastructure, and tools that people need to perform practices. Materiality is what brings consumption into the discussion of practices (Warde 2005). Thus, practice theory and sustainable consumption research are linked through the material component of practices (Sahakian and Wilhite 2013). The material components are also usually the reason why the practice is considered unsustainable. Moreover, the practice theory perspective enables one to focus on doing rather than having products (Shove et al. 2012). Furthermore, the theory is suitable for this particular study especially because it does not focus on individual decision-making and does not view consumers as catalysts or barriers to change, but instead focuses on consumption bound up with everyday social life (Sahakian and Wilhite 2013). In addition, the astatic nature of social practices as well as the interrelations between practices makes it an interesting theory for the context (Shove and Pantzar 2005). Performing practices usually involves various products and other material artefacts, raising the importance of consumption. Material 
artefacts have agency once they are taken into use (Sahakian and Wilhite 2013). The aim is to move the negative discussion of sustainable consumption research about overconsumption towards a broader view of materials in practices. Specifically, the dissertation illustrates how it is useful to understand the role of material artefacts and tasks related to product ownership, such as maintenance, in order to have a holistic understanding of the problems behind the unsustainable practices. 


\section{Methodology}

In this dissertation, ethnography has been the guiding principle for doing qualitative research. The method provided a perfect fit to gain understanding of everyday practices in order to understand how product use contributes to the sustainability of the products. Ethnography is also suitable for the theoretical perspective of practice theory for bringing up all practice elements: the materials, meanings and competences. The method similarly provided a great fit to the chosen research context of leisure boat maintenance, which is a highly embodied practice that would not have been comprehensively understandable through spoken language, for example. In practice, this has meant participating in boat maintenance practices for extended periods, observing boat owners and the boat communities, asking questions regarding people's everyday lives while they participate in maintaining their boats, and boat owners reflecting on their experiences, as well as reading the news and other secondary sources in order to get a holistic picture of boating and boat maintenance as a practice. Since the method used for answering each research question, as well as the data collection process and analysis, is described in more detail in each of the essays, this chapter discusses the origins of ethnography and then moves onto describing how ethnography is used in consumer research and sustainable consumption at large. I then introduce the context of my research, which is then followed briefly by my account of the data collections and analysis.

\subsection{Ethnography as a method}

Ethnography refers to "a research process in which the researcher is closely engaged in the daily life of some social setting and collects data using ethnographic methods of observations and participation - an experience labeled as fieldwork - and then writes accounts of this process" (Moisander and Valtonen 2006, p. 45). Ethnography is both a way of interpreting culture and a data collection method (Geertz 1973; Arnould 1998; Sherry 2008). The method originates from cultural anthropology, where ethnography was mainly used for studying small-scale societies (Goulding 2005). Yet, where ethnography as a methodology was previously used for studying distant and exotic places (Geertz 
1973), it is nowadays increasingly used to understand familiar contemporary cultures closer to home (Moisander and Valtonen 2006, p. 47). As a result, besides the geographical change, the method has also evolved theoretically and diversified (Moisander and Valtonen 2006, p.47).

Ethnography has gained popularity increasingly in marketing and consumer research (Arnould and Wallendorf 1994). Ethnography is used especially in contemporary consumer culture, as it makes it possible to explore consumption beyond cognition and behavior by giving more understanding of the social and cultural point of view (Arnould 1998). The early examples from ethnography in consumer research began with what is known as the Consumer Behavior Odyssey, in which researchers aimed to acquire knowledge about American consumption by travelling with a recreational vehicle around the United States and employing ethnographic methods such as videotaping in-situ interviews, taking photos and writing fieldnotes on consumption activities (Belk et al. 1988; McGrath et al. 1993). Since then, ethnography has been increasingly used in studying everyday cultural consumption (Arnould and Wallendorf 1994; Arnould and Thompson 2005, Kozinets 2010). It is widely used in consumer culture theory studies, for example in understanding subcultures in the context of Harley Davidson motorcycle fans (Schouten and McAlexander 1995), experiential servicescapes in the context of whitewater rafting (Arnould and Price 1993), sociocultural branding in the context of the American Girl brand (Diamond et al. 2009), and extraordinary experiences and pain in the context of the Tough Mudder adventure challenge (Scott et al. 2017), to name a few. The method is especially useful for the present study because of ethnography's focus on observing consumers in their everyday life while they are carrying out their practices (Reckwitz 2002).

Ethnography enables researchers to go beneath superficial or socially desirable meanings (Goulding 2005) and helps to understand the culturally-shaped actions and everyday social interactions (Arnould and Wallendorf 1994; Arnould and Thompson 2005). The main goal of ethnography is to systemically clarify the behaviors of members that construct and are constructed by the culture (Goulding 2005). Arnould and Wallendorf (1994) summarize four essential characteristics of ethnographic interpretation: 1) primacy to systematic studying of human action in natural settings, 2) extended, experiential participation in the studied cultural context, 3) production of interpretations of behaviors which the studied persons and the intended audience evaluate as credible, 4) incorporation of multiple sources of data.

Ethnography aims to explain how culture is constructed in a particular cultural context (Sherry 2008), studying social phenomena in situ (Moisander and Valtonen 2006, p. 48). It is mostly about how experiences in the society reflect meanings for individuals (Arnould 1998). Ethnographers aim to look "beyond what people say to understand the shared system of meanings" (Goulding 2005, p. 298) and observe behaviors that naturally occur (Arnould and Wallendorf 1994) while being faithful to the experiences of a specific chosen context (Sherry 2008). However, ethnographers do not presume a field or setting as such, but 
analyze it in ways through which it is formed through discourse and material practice (Moisander and Valtonen 2006, p. 51).

Ethnographic data collection includes collecting data from multiple sources for an extended period of time. Sherry (2008) provides a toolkit which is typically included in ethnographies: archival analysis, trace analysis, participant observation, interviews, photography, videography, and projective tasking. The success lies within applying these multiple methods into a single phenomenon (Arnould 1998). To collect data from multiple sources is, of course, time-consuming and labor intensive (Goulding 2005). Yet, extensive fieldwork and faceto-face interaction in people's natural settings is necessary for ethnography, as it provides a deeper understanding of the ways in which people make sense of their lives (Arnould 1998; Moisander and Valtonen 2006, p. 48) and improves the likelihood of getting holistic explanations (Sherry 2008). Participant observation is an especially central data collection method, as it allows access to the details of consumption behavior (Arnould and Wallendorf 1994) and enables giving meaning to the cultural patterns (Arnould 1998).

Ethnographic data collection results in a written end-product where the voices of participants in the cultural context are constructed in a fluent and readable narrative (Sherry 2008). The research findings should represent the multitude of layered meanings (Arnould 2008). However, an important notion with regard to the researchers' positioning is that the researcher is always affected by the world which is under study (Boyle 1994). Consequently, the researcher combines both the outsider interpretations (etic) with the subjective insider experiences (emic) to provide deep and holistic insights and understandings (Boyle 1994; Arnould and Wallendorf 1994; Goulding 2005). Also, ethnography's aim is to provide meanings and understandings rather than to generalize (Arnould 1998).

\subsection{Research methods and data}

Ethnography proved beneficial to studying sustainable consumption practices during product use since it enabled getting a holistic understanding of a difficult, multi-layered problem. The method allowed going beyond the attitude-behavior problematics by looking beyond the spoken language, while simultaneously getting into the meanings behind product use. Ethnography has been increasingly used to study consumer practices in the context of environmental behavioral change (Hargreaves 2011) and sustainable consumption (Casey, Lichrou, and O'Malley 2017). Ethnographic research is useful for the context as it facilitates firsthand understanding of the doings and sayings of consumers in their everyday consumption practices (Shove and Pantzar 2005; Shove, et al. 2012).

One of the methodological questions to ask was how much voice I had to or should give to the boat owners, especially considering that previous attitude-behavior gap studies have proven multiple times that people tend to 
say one thing but behave in another way. This question confirmed the method choice to include not only spoken language, namely interviews, but also participant observation in situ, in order to experience myself how the practices were structured. Moreover, according to for example Schatzki (2002), sayings are a subset of doings, and therefore they are doings that say something. Additionally Shove et al. (2012) outline that practices are entities that can be spoken about. Yet, practice theories decentralize the subject by focusing on both sayings and doings (Warde 2005). This is where ethnography also proved useful, as it allowed taking a decentralized perspective, while interviewing alone might disregard the material surroundings.

The rich data was gathered through formal interviews as well as participant observation and informal conversations which took place in the everyday practices. The interviews were designed to help informants reflect on their past behaviors and future expectations (Arnould and Wallendorf 1994). Participant observation made it possible to study the relationships among people, organization of their doings, and different patterns as well as the immediate sociocultural context (Jorgensen 1989). The data collection for the dissertation began in March 2015 and ended in November 2018. This long-term immersion in the boat maintenance context enabled studying the consumer behavior as it occurred (Arnould and Wallendorf 1994). Through extensive participant observations at multiple boatyards, I was granted an access to the behind-the-scenes activities which might have been otherwise hidden. For example, a harbormaster who I got to know very well during multiple visits at the boatyard showed me stains of antifouling paint on the ground. He told me to not take pictures and told me how they were not proud of those stains. Additionally, the multinational and -disciplinary research team provided access to different domains of meaning. For example, many boat owners treated me, a young female, as someone who did not have much knowledge on how the boat functioned. Therefore, the boaters explained to me in great detail what they were doing with their boats, especially when it came to anything technological. In retrospect, this was beneficial for me, as they might have left out some interesting aspects had they thought I was an expert. Similarly, collecting data in Finland proved much easier than elsewhere due to the language and culture barriers elsewhere.

As cultural meanings, ideals and practices are not tied to a geographic space (Appadurai 1996), we collected data not only at the boatyards where the maintenance happened. We also visited boat fairs, did informal observation in online boating forums, and read newspapers and boating magazines. Therefore, an essential part of understanding how the practice is formulated was constituted in the online forums where boat owners shared knowledge and tips on boat maintenance and also discussed the environmental worries related to boat maintenance. Extensive participation in the field enabled me to get an 'insider' perspective (Moisander and Valtonen 2006, p. 51). The observations permitted me to explore the mundane everyday maintenance practices the boat owners did not recognize doing even themselves (Moisander and Valtonen 2006, p.52).

My stance when starting with this research was not neutral. As mentioned, ideal for doing ethnographic research is that the researcher 
immerses him- or herself into the site for an extended period of time. I am a beginner sailor myself. I started my sailing journey in 2011 by attending a scout group evening sailing. I then found sailing so fascinating that I went along to longer, around one-week long sailing trips and took courses on navigating. I did not engage much with boat maintenance, other than the maintenance which took part during the sailing trips. I was first exposed to boat maintenance only when I joined the research project. Once I got into the research project and learned more about the maintenance practices, I went along and maintained the scout boat. I also helped out at friends' boats. Therefore, I cannot say I was an outsider when I started and neither did I have a "blank state". My previous experiences gave me some insider advantages, as I had some information before entering the field as a researcher. However, to distance myself from the research context, I started with the research by going to a boatyard I had not previously been to, and talked with boat owners I did not know beforehand. It was easier to have conversations with the boat owners knowing a little about sailing. However, I did not have much experience on motorboating, and most of the information I heard from the informants about boat maintenance was new to me.

As the data was collected within a larger research group, the data analysis was an ongoing process throughout the project and yielded multiple reports and articles. The analysis brought the product circularity and sustainability into the center of the research. The initial focus at the start of the research was understanding unsustainable boat maintenance practices, but through analysis, the focus evolved into understanding product use, maintenance and sustainability at a larger scale. The three essays presented in this dissertation were produced through an extensive data analysis process. I was responsible for the first round of analysis for all the essays. The data analysis started with the traditional ethnographic data analysis process, namely looking for patterns from the interview transcripts (Goulding 2005). I identified categories that were then placed under broader themes. This coding process then lead to a synthetization, where the categories were linked (Goulding 2005). I first started analyzing the data through open coding and coupled the analysis with the fieldwork findings, while adhering to the recommended iterative process ongoing throughout the research project (Belk, Fischer, and Kozinets 2012). I then applied the practice theory framework to analyze the qualitative data, allowing me to examine materiality, competence and meaning from the emic perspective of boat owners. By employing hermeneutical analysis (Spiggle 1994) I was able to develop a sense of the whole (Arnold and Fischer 1994).

\subsection{Context}

The dissertation is based on an EU funded research project, CHANGE (changing antifouling practices for leisure boats in the Baltic Sea). It was a multidisciplinary project among marine scientists, legal scholars and consumer researchers to comprehensively examine leisure boat maintenance practices around the Baltic Sea. Maintenance of the boat hull is particularly implicated in 
environmental sustainability, as the hull interacts with the marine environment while in use and the land environment during maintenance and storage.

Most leisure boat owners use toxic antifouling (AF) paint to keep barnacles from attaching to the hull (see picture 1), thereby improving maneuverability and decreasing drag, which in turn lessens fuel consumption and costs. AF paint used to combat barnacles causes particular problems, as the use of these products continuously adds to the distribution of biocides in the coastal ecosystem (Thomas and Brooks 2010) and leads to the unintended deaths of benign marine organisms. The more toxic anti-fouling paints containing tributyltin (TBT) were banned in the European Union already in 1989. Yet, the copper and zinc in current anti-fouling paints have also been proven harmful for species in the Baltic Sea and thereafter to its whole ecosystem (Lageström et al. 2017). Additionally, TBT is still present in old layers of paint on nearly $50 \%$ of leisure boats in the Baltic Sea (Eklund et al. 2008). The effects to the Baltic Sea are especially severe considering the brackish-water ecosystem and the wide range of salinity (Dahlström et al. 2018). In fact, the Baltic Sea is one of the most polluted seas in the world (Helcom 2010). All three essays are based on data collected during the project and the results are used by environmental organizations such as Keep the Archipelago Tidy, as well as the Ministry of the Environment and Finnish Safety and Chemicals Agency.

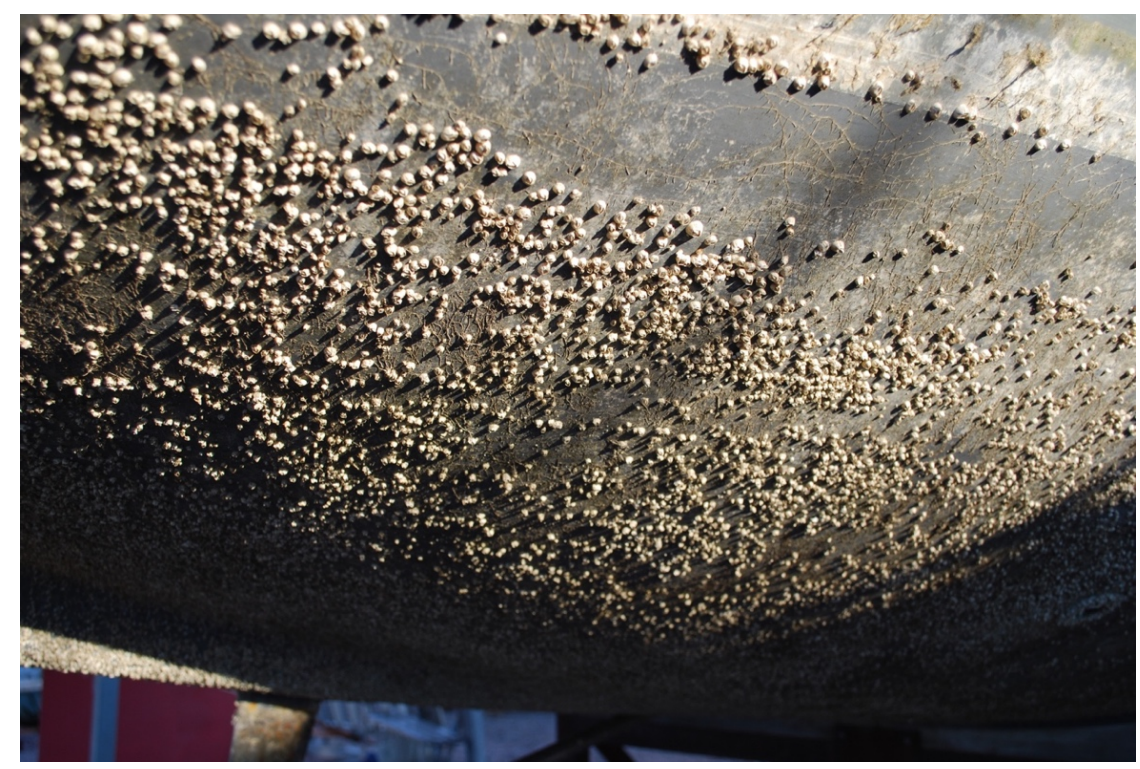

Picture 1. Barnacles attached to a boat hull 


\subsection{Context of context}

In order to guide the reader into the specifics of the context of context (Askegaard and Linnet 2011), here I will give a brief outline of boat maintenance in the Nordics, whereas essay 2 will more thoroughly explain the specifics of Nordic restrictions and freedoms. The cold weather conditions dictate boat maintenance practice in the Nordics. In the autumn, boats are moved onto land and washed with high-pressure hoses and covered with protective tarps for the long winter storage (see picture 2). These winter storage sites vary from sailors' backyards to indoor halls operated by private businesses. However, most boats are stored in private and public outdoor boatyards. A major part of boat maintenance happens in the springtime, starting from March-April, when the boats are prepared for the sailing season. The springtime maintenance consists of washing the boat, waxing its sides, replacing broken or rusty materials, fixing the engine if needed, and painting the hull with toxic paints to avoid the biological contamination of barnacles and algae. Little maintenance takes place during the actual sailing season; that is mainly dedicated to the actual sailing practice. During the sailing season, the maintenance is mainly responsive damage control and aesthetic adjusting of polishing the sides of the boat and checking the conditions of for example ropes and sails.

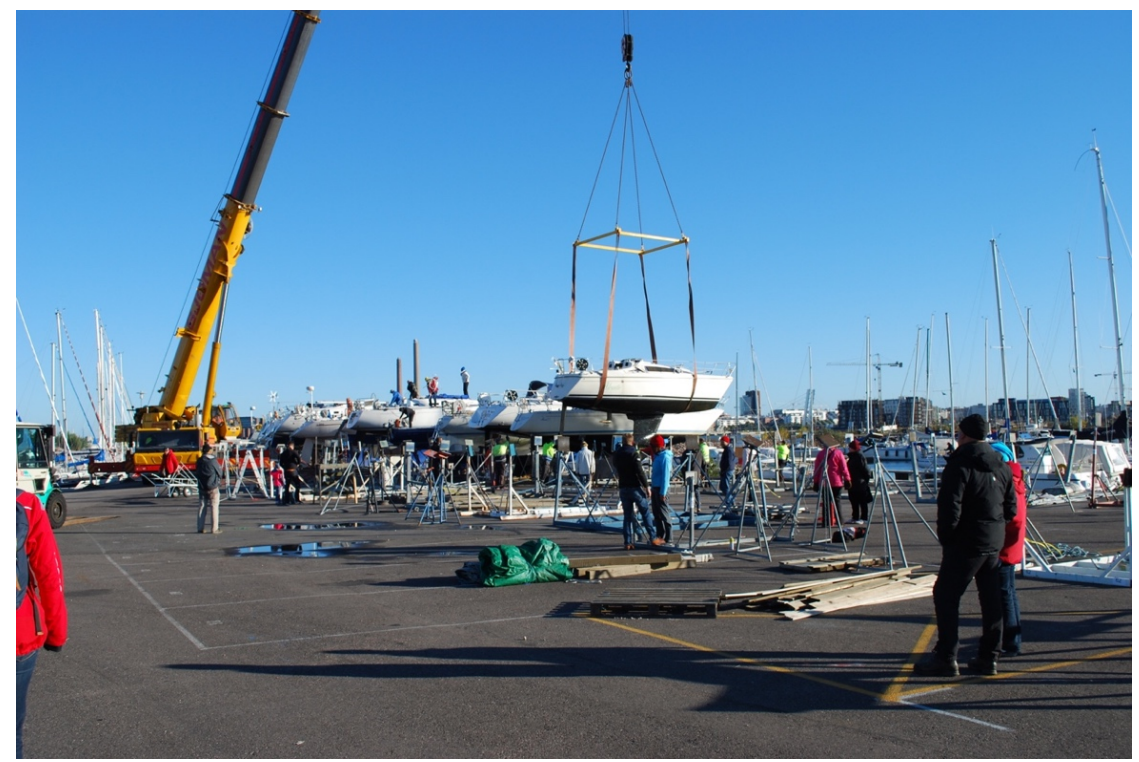

Picture 2. Sailboats lifted to the winter storage area in Helsinki next to a harbor

Nature plays an important part in Nordic life (Beery 2013). In the Nordics, "real" boating is traditionally associated with an image of getting "back to one's roots". It often involves some ascetic elements and peace, requiring a considerable amount of personal maintenance work and know-how. Therefore, the barriers to enter the hobby are generally quite high, not necessarily in terms of money, but in terms of needing a high personal involvement in time and know- 
how. Thus, the hobby can be seen burdensome at times, as it may require high time investment. Modern technology may even make the maintenance increasingly more difficult, since self-maintenance requires even more extensive education and know-how. However, the government supports boating by offering infrastructure for boating, such as relatively cheap boat spots in harbors close to city centers. The Nordic states have a strong aim of interfering in what people do and how they think (Østergaard et al. 2014). Yet, a Nordic specialty is the concept of everyman's rights which allow everyone an equal opportunity to enter and experience nature (Beery 2011). 


\section{Conclusions and summary of find- ings}

This section introduces how the findings of the three essays bring new perspectives to sustainable consumption practices through product use. All three essays focus on studying the same consumption practice: boating and related boat maintenance as a way to support product life-extensions. To shed light on consumer roles in the circular economy which have up to now not been studied, the three essays deal with the intersection of macro, meso and micro perspectives. Yet, it is important to keep in mind that the practice theory approach permits focusing on social processes (Schatzki 2002) and looking at practice configurations as a whole, without demanding a separation between macro and micro perspectives. Therefore, the practice theory perspective makes it possible to situate consumer behavior into a greater totality and move between micro, meso and micro perspectives. This allows for moving away from the attitude-behavior gap (Young and Middlemiss 2012) and getting a more holistic view of product use in the full consumption cycle (Prothero et al. 2011).

Next, I will explain how each of the essays answers the main research question through the macro-meso-micro perspectives. However, it is not my intention to repeat all of the findings of the essays, but rather to highlight the main contributions in answering the main research question.

\subsection{Essay I: More Than One Way to Float Your Boat: Product Use and Sustainability Impacts}

The first essay explores how different variations of materials, meanings and competences result in different sustainability impacts. The essay broadens understanding about how different practice configurations impact the sustainability of product use. By doing this, it brings all macro, meso, and micro levels into the discussion. It argues that on one hand, previous macro level research on sustainability has focused on institutional actors and systemic change efforts (e.g. Thøgersen 2005; Prothero et al. 2011; Holt 2012; Chatzidakis, Maclaran, and Bradshaw 2012; Yngfalk 2016). On the other hand, the micro level research on sustainable consumption has mainly focused on consumer choice and postuse disposal (e.g. Benton 2015; Brosius, Fernandez, and Cherrier 2013; Lastovicka and Fernandez 2005). The essay then takes a practice theory perspective 
and looks at both macro and micro levels, such as institutional regulations and market resources (macro) and cultural expectations (micro). For example, the study shows that existing infrastructures and institutional actions shape the practices during product use. Additionally, the study shows how practice configuration variability has direct consequences on the environmental impact of paint use. The essay emphasizes the need for institutional actors to take action. Yet, it also argues that more sustainable use practices are enforced at the meso and micro levels. Without community surveillance of local norms, the macro level regulations would remain ineffective.

The essay identifies four different practice configurations - the Proper Boater, Opportunist, Green Boater and Negotiator. These four configurations illustrate how choosing different materials during product use results in more or less sustainable product use. For example, in addition to the boat, the sea, and the human bodies carrying out the maintenance practice, material elements of the practice include the paint, brushes, tarps and other equipment used in maintenance; rules and regulations guiding or restricting the activity; and the overall marina infrastructure, including recycling bins for waste management. The findings also show that the EU, local laws, enforcement of regulations and the boat community values also contribute to product use sustainability. Hence, the essay helps in understanding the motifs of the most sustainable consumers and gives more insights to the meanings of the unsustainable practices.

By looking at the macro, meso, and micro levels through materials, competences and meanings, the essay brings a more holistic view of the full consumption cycle (Prothero et al. 2011). The essay illustrates the complexity of institutional versus communal efforts shaping sustainable practices. For product circularity to become actualized at the consumer level, not only should institutional actors take action through for example regulations, but also the communities should be activated and included.

\subsection{Essay II: Experiencing Nature through Nordic Restrictions and Freedom}

The second essay similarly focuses on both macro and micro levels. Most importantly, this essay contextualizes the consumers' lived experiences and how they are structured by the social systems and markets. The essay brings a more holistic approach to sustainable consumption by exploring the context of context (Askegaard and Linnet 2011) - explaining the forces that shape the lived experiences of consumers. This makes it possible to escape the individualistic approach to consumption and product use by taking into account how the usage practice is situated in space, emphasizing the social structure of behavior (Spaargaren 2002). Hence, the essay looks more deeply into macro-social structures than the other two essays. Moreover, the essay illustrates how nature ideologies are essential for understanding sustainable product use. Therefore, the essay goes into the specifics of experiencing nature in the Nordic context. 
Even though the Nordic region shares many similarities with other Western cultures, the Nordic model still shapes sustainable consumption practices. Nordic nature experiences are full of paradoxes which consumers need to navigate through. On one hand, a Nordic specialty is the freedom brought by the everyman's rights, which allow each and every person a free access to nature. However, the freedom is somewhat illusional, since the Nordic welfare states are also well known for their strict governmental restrictions. This macro level perspective allows a broader understanding of why and how nature is experienced, which then further helps with giving context to how consumers could be engaged into sustainability. The essay also brings the micro perspective to how consumers themselves see sustainability. For example, the findings show that even though the common ideology in the welfare states follows the idea that everything ought to come as given to citizens (Kjelgaard and Östberg 2007), the responsibility has not shifted entirely away from the consumer. This is because of the communities adhering to the egalitarian ethos. Therefore, the nature ideologies are an important part of understanding consumers' roles in making consumption practices sustainable.

The essay helps to give more understanding, through context of context, on why boaters chose or did not choose the more sustainable options. Also, this study shows how the practice of sailing is organized through the government, municipalities and boating communities. Interestingly, for example, Nordic sailors were often outsourcing morality to the government (Byrkjeflot 2001) by requesting that the government take more responsibility, and not being proactive themselves. Similarly, consumers were constantly balancing between public collectivism and private individualism (Berggren and Trägårdh 2010). Following the Nordic egalitarian ethos, everyone was required to participate in the communal maintenance efforts. Yet, individuals were authorized (Giesler and Veresiu 2014) to take actions independent of the state.

To get a holistic view of how to achieve sustainable consumption in regards to product use, this essay brings more insight into the effects of surrounding consumer culture. Accordingly, the essay suggests that sustainable product use cannot be achieved simply by focusing on the features of the products during the manufacturing process; the social structures in which the practices are embedded should also be considered. Additionally, nature ideologies are shown to dictate maintenance practices to some extent, and hence should not be disregarded.

\subsection{Essay III: Maintenance Practices in Communal Consumption: An Ethnography of Baltic Sea Sailors}

The third essay gives important information especially on the micro and meso level of product use. It provides implications to circularity from a consumer perspective by explaining how consumers participate in lengthening product life spans. Most importantly, the essay shows the active role of consumers by 
demonstrating their ability and willingness to maintain products. The essay goes more deeply into the different practice elements comprising of maintenance. It elaborates why consumers engage in maintenance practices and what it means for them. Additionally, by deepening the analysis of the meso level, the essay provides more insight into theorization of communal practices.

At the micro level, the essay explains how and why individuals engage with maintenance practices. Maintenance, for example, not only ensures that objects continue to serve their practical purpose, but also connects to symbolic teleoaffective ends. In the context of sailing and sailboat maintenance, the maintenance of the boats cannot be separated from the overall practice of sailing. Hence, maintenance predominantly links to usage. We usually maintain things which we like and actively use (e.g. Belk 1988; Epp and Price 2010). The essay also shows the role of maintenance in acquisition practices where new possessions are adjusted (McCracken 1986; Fernandez and Lastovicka 2005). Similarly, the disposal of objects may entail maintenance, for example to increase the exchange value or to give a symbolic farewell (e.g. Fernandez and Lastovicka 2005; Türe 2014). Hence, we show how maintenance cuts through the entire consumption chain of acquisition, usage, and disposal (Holbrook 1987), linking to the first essay.

At the meso level, the essay explains how consumers join consumption communities to deepen their consumption engagements (Schouten and McAlexander 1995; Schau et al. 2009; Arnould and Thompson 2018) and develop consumption competencies (Schau et al. 2009; Thomas et al. 2013). The sailing communities orchestrate maintenance practices by providing access to maintenance resources, but they also discipline these maintenance practices. The macro level, which we frame as the consumptionscape of sailing, is made up of man-made structures, climate, geography, maritime meanings and mythologies, nature discourses and networks of consumption communities. Here, maintenance serves as a way to create a better fit between the boat and the macro structures of the consumptionscape. This relates to the findings of essay 2, where consumers not only maintain their boats for material fits, but also to fit the Romantic imaginary realm (see also Canniford and Shankar 2012). Additionally, the essay emphasizes how maintenance is best understood as a nexus of practices (Shove et al. 2012) to expand the view of usage from the objectcentric view, where consumers only exert effort to preserve their desired levels of functionality (e.g. Takata et al. 2004). In other words, maintenance does not only shape the objects under care-it transforms practitioners, communities, and consumption experiences.

By taking the communal level into focus of the discussion, the third essay elaborates how and why consumers engage in enhancing product circularity, especially communally. Rather than considering consumers passive recipients, the focus on maintenance brings up the joy of extending product lifecycles and hence the deeper meanings of the maintenance practice. Additionally, the essay emphasizes that lengthening product lifecycles through maintenance does not relate only to product use, but is further extended to acquisition and disposal. 


\subsection{Limitations and future research avenues}

The findings of this dissertation need to be interpreted in light of its limitations. The limitations addressed here provide fruitful opportunities for future research in sustainability, circular economy and consumer research.

Firstly, the context of the study limited it to sustainable consumption practices during product use. Future research should continue the focus on how consumers are taking an active role in the circular economy. Whereas the essays focused on maintenance and extending product lifecycles, other areas where consumers take an active role in enhancing product circularity should be explored. Hence, to gain deeper insight into product circularity from the consumer perspective, it would be interesting to study product use in a more consumer-driven circular economy. This would enhance the circular economy future by involving all actors into moving from linear to circular. Similarly, where boat maintenance relates to lengthy ownership, future research should look into contexts where ownership is usually shorter, such as clothing.

Secondly, my research focused on the Baltic Sea and especially on consumer practices in Finland, Sweden, Germany and Denmark. Expanding the research focus to other Baltic Sea states and further outside the Baltic Sea area would provide a broader perspective into sustainable consumption practices during product use. As mentioned, the Nordic model orchestrates the practices. For example, the relationship to nature might be different in other contexts and result in different findings.

Thirdly, looking at sharing economy and collaborative consumption could benefit from a circular economy approach, especially studying the collaboration between consumers, producers, and other stakeholders. As mentioned, I argue that the need for maintenance may become even more extensive when moving towards sharing or circular economy, where the products circulated and shared need to be kept in good condition. Hence, we need more information on how consumers could be taken into consideration when planning product circularity through new innovative business models advocating access instead of ownership. 



\section{References}

Ahuvia, A. C. (2005). Beyond the extended self: Loved objects and consumers' identity narratives. Journal of consumer research, 32(1), 171-184.

Ajzen I (1991) The theory of planned behavior. Organizational Behavior andHuman Decision Processes 50: 179-211.

Alexander, S., \& Ussher, S. (2012). The voluntary simplicity movement: A multi-national survey analysis in theoretical context. Journal of Consumer Culture, 12(1), 66-86.

Arnold, S. J., \& Fischer, E. (1994). Hermeneutics and consumer research. Journal of Consumer Research, 21(1), 55-70.

Arnould, E. J. (1998). Daring consumer-oriented ethnography. Representing consumers: Voices, views and visions, 85-126.

Arnould, E. J. (2007). Should consumer citizens escape the market?. The Annals of the American Academy of Political and Social Science, 611(1), 96-111.

Arnould, E. J., \& Price, L. L. (1993). River magic: Extraordinary experience and the extended service encounter. Journal of consumer Research, 20(1), 24-45.

Arnould, E. J., \& Thompson, C. J. (2005). Consumer culture theory (CCT): Twenty years of research. Journal of consumer research, 31(4), 868-882.

Arnould, E. J., \& Thompson, C. J. (Eds.). (2018). Consumer culture theory. Sage.

Arnould, E. J., \& Wallendorf, M. (1994). Market-oriented ethnography: interpretation building and marketing strategy formulation. Journal of marketing research, 31(4), 484-504.

Arsel, Z., \& Bean, J. (2013). Taste regimes and market-mediated practice. Journal of Consumer Research, 39(5), 899-917.

Askegaard, S., \& Linnet, J. T. (2011). Towards an epistemology of consumer culture theory: Phenomenology and the context of context. Marketing Theory, 11(4), 381-404.

Assadourian, E. (2010). Transforming cultures: From consumerism to sustainability. Journal of Macromarketing, 30(2), 186-191.

Bakker, C., den Hollander, M., Van Hinte, E., \& Zljlstra, Y. (2014b). Products that last: Product design for circular business models. TU Delft Library.

Bakker, C., Wang, F., Huisman, J., \& Den Hollander, M. (2014a). Products that go round: exploring product life extension through design. Journal of Cleaner Production, 69, 10-16.

Bardhi, F., \& Eckhardt, G. M. (2012). Access-based consumption: The case of car sharing. Journal of consumer research, 39(4), 881-898.

Bardhi, F., Eckhardt, G. M., \& Arnould, E. J. (2012). Liquid relationship to possessions. Journal of Consumer Research, 39(3), 510-529. 
Bartiaux, F. (2008). Does environmental information overcome practice compartmentalisation and change consumers' behaviors?. Journal of Cleaner Production, 16(11), 1170-1180.

Becker-Leifhold, C. V. (2018). The role of values in collaborative fashion consumptionA critical investigation through the lenses of the theory of planned behavior. Journal of cleaner production, 199, 781-791

Beery, T. H. (2013). Nordic in nature: friluftsliv and environmental connectedness. Environmental Education Research, 19(1), 94-117.

Belk, R. (2009). Sharing. Journal of consumer research, 36(5), 715-734.

Belk, R. (2014). You are what you can access: Sharing and collaborative consumption online. Journal of business research, 67(8), 1595-1600.

Belk, R. (2014). You are what you can access: Sharing and collaborative consumption online. Journal of business research, 67(8), 1595-1600.

Belk, R. (2017). Sharing without caring. Cambridge Journal of Regions, Economy and Society, 10(2), 249-261.

Belk, R. W. (1988). Possessions and the extended self. Journal of consumer research, 15(2), 139-168.

Belk, R. W., Sherry Jr, J. F., \& Wallendorf, M. (1988). A naturalistic inquiry into buyer and seller behavior at a swap meet. Journal of Consumer Research, 14(4), 449470.

Belk, R., Fischer, E., \& Kozinets, R. V. (2012). Qualitative consumer and marketing research. Sage.

Benton Jr, R. (2015). Reduce, Reuse, Recycle... and Refuse. Journal of Macromarketing, 35(1), 111-122.

Berggren, H., \& Trägårdh, L. (2010). Pippi Longstocking: The autonomus child and the moral logic of the Swedish welfare state.

Bertilsson, J. (2015). The cynicism of consumer morality. Consumption Markets \& Culture, 18(5), 447-467.

Binninger, A. S., Ourahmoune, N., \& Robert, I. (2015). Collaborative Consumption And Sustainability: A Discursive Analysis Of Consumer Representations And Collaborative Website Narratives. Journal of Applied Business Research (JABR), 31(3), 969-986.

Bocken, N. M., De Pauw, I., Bakker, C., \& van der Grinten, B. (2016). Product design and business model strategies for a circular economy. Journal of Industrial and Production Engineering, 33(5), 308-320.

Bocken, N. M., Ritala, P., \& Huotari, P. (2017). The circular economy: exploring the introduction of the concept among S\&P 500 firms. Journal of Industrial Ecology, 21(3), 487-490.

Boulding, K. (1966). E., 1966, the economics of the coming spaceship earth. New York.

Boyle, J. S. (1994). Styles of ethnography. Critical issues in qualitative research methods, $2,159-85$.

Brosius, N., Fernandez, K. V., \& Cherrier, H. (2013). Reacquiring consumer waste: Treasure in our trash?. Journal of Public Policy \& Marketing, 32(2), 286-301.

Bulkeley, H., \& Gregson, N. (2009). Crossing the threshold: municipal waste policy and household waste generation. Environment and planning A, 41(4), 929-945.

Byrkjeflot, H. (2001). The Nordic model of democracy and management. The democratic challenge to capitalism: Management and democracy in the Nordic countries, $19-45$.

Camacho-Otero, J., Boks, C., \& Pettersen, I. (2018). Consumption in the circular economy: A literature review. Sustainability, 10(8), 2758. 
Canniford, R., \& Shankar, A. (2012). Purifying practices: How consumers assemble romantic experiences of nature. Journal of Consumer Research, 39(5), 1051-1069.

Carrington, M. J., Neville, B. A., \& Whitwell, G. J. (2014). Lost in translation: Exploring the ethical consumer intention-behavior gap. Journal of Business Research, 67(1), 2759-2767.

Casey, K., Lichrou, M., \& O’Malley, L. (2017). Unveiling everyday reflexivity tactics in a sustainable community. Journal of Macromarketing, 37(3), 227-239.

Chalmers Thomas, T., Price, L. L., \& Schau, H. J. (2012). When differences unite: Resource dependence in heterogeneous consumption communities. Journal of Consumer Research, 39(5), 1010-1033.

Chappells, H., \& Trentmann, F. (2015). Sustainable consumption in history: Ideas, resources and practices. Handbook of research on sustainable consumption, edited by Lucia A. Reisch, and John Thøgersen, 51-70.

Chatzidakis, A., Maclaran, P., \& Bradshaw, A. (2012). Heterotopian space and the utopics of ethical and green consumption. Journal of Marketing Management, 28(3-4), 494-515.

Cherrier, H. (2009). Anti-consumption discourses and consumer-resistant identities. Journal of Business Research, 62(2), 181-190.

Cherrier, H. (2010). Custodian behavior: A material expression of anti-consumerism. Consumption, Markets and Culture, 13(3), 259-272.

Cherrier, H., \& Murray, J. B. (2007). Reflexive dispossession and the self: constructing a processual theory of identity. Consumption Markets \& Culture, 10(1), 1-29.

Cherrier, H., Black, I. R., \& Lee, M. (2011). Intentional non-consumption for sustainability: consumer resistance and/or anti-consumption?. European Journal of Marketing, 45(11/12), 1757-1767.

Clark, G. (2007). Evolution of the global sustainable consumption and production policy and the United Nations Environment Programme's (UNEP) supporting activities. Journal of cleaner production, 15(6), 492-498.

Cohen, M. J. (2006). Sustainable consumption research as democratic expertise. Journal of consumer policy, 29(1), 67-77.

Colicchia, C., Marchet, G., Melacini, M., \& Perotti, S. (2013). Building environmental sustainability: empirical evidence from Logistics Service Providers. Journal of Cleaner Production, 59, 197-209.

Connolly, J., \& Prothero, A. (2003). Sustainable consumption: consumption, consumers and the commodity discourse. Consumption, Markets and Culture, 6(4), 275-291.

Cooper, T. (2004). Inadequate life? Evidence of consumer attitudes to product obsolescence. Journal of Consumer Policy, 27(4), 421-449.

Cooper, T. (2005). Slower consumption reflections on product life spans and the "throwaway society". Journal of Industrial Ecology, 9(1-2), 51-67.

Cooper, T. (Ed.). (2016). Longer lasting products: Alternatives to the throwaway society. CRC Press.

Craig-Lees, M., \& Hill, C. (2002). Understanding voluntary simplifiers. Psychology \& Marketing, 19(2), 187-210.

Dahlström, M., Dahlström,M., Elwing, H., Ytreberg, E., Solér, C. (2014). Bland borsttvätter och fartygsfärger. En studie av fritidsbåtägares attityder till och användning av olika antifoulingtechniker.

Devinney, T. M., Auger, P., \& Eckhardt, G. M. (2010). The myth of the ethical consumer hardback with DVD. Cambridge University Press. 
Diamond, N., Sherry Jr, J. F., Muniz Jr, A. M., McGrath, M. A., Kozinets, R. V., \& Borghini, S. (2009). American Girl and the brand gestalt: Closing the loop on sociocultural branding research. Journal of Marketing, 73(3), 118-134.

Dolan, P. (2002). The sustainability of "sustainable consumption". Journal of Macromarketing, 22(2), 170-181.

Eklund, B., \& Eklund, D. (2014). Pleasure boatyard soils are often highly contaminated. Environmental management, 53(5), 930-946.

Elkington, J. (1998). Partnerships from cannibals with forks: The triple bottom line of 21st-century business. Environmental quality management, 8(1), 37-51.

Epp, A. M., \& Price, L. L. (2011). Designing solutions around customer network identity goals. Journal of Marketing, 75(2), 36-54.

European Commission, 2014. Towards a Circular Economy: A Zero Waste Programme for Europe, $\operatorname{COM(2014)} 398 \mathrm{Final} / 2$. Brussels, Belgium.

Fishman, A., Gandal, N., \& Shy, O. (1993). Planned obsolescence as an engine of technological progress. The Journal of Industrial Economics, 361-370.

Follows, S. B., \& Jobber, D. (2000). Environmentally responsible purchase behavior: a test of a consumer model. European journal of Marketing, 34(5/6), 723-746.

Geertz, C. (1973). The interpretation of cultures (Vol. 5019). Basic books

Ghisellini, P., Cialani, C., \& Ulgiati, S. (2016). A review on circular economy: the expected transition to a balanced interplay of environmental and economic systems. Journal of Cleaner production, 114, 11-32.

Giesler, M., \& Veresiu, E. (2014). Creating the responsible consumer: Moralistic governance regimes and consumer subjectivity. Journal of Consumer Research, 41(3), 840-857

Goulding, C. (2005). Grounded theory, ethnography and phenomenology: A comparative analysis of three qualitative strategies for marketing research. European journal of Marketing, 39(3/4), 294-308.

Guiltinan, J. (2009). Creative destruction and destructive creations: environmental ethics and planned obsolescence. Journal of business ethics, 89(1), 19-28.

Gupta, S., \& Ogden, D. T. (2009). To buy or not to buy? A social dilemma perspective on green buying. Journal of Consumer Marketing, 26(6), 376-391.

Halkier, B., Katz-Gerro, T., \& Martens, L. (2011). Applying practice theory to the study of consumption: Theoretical and Metholodogical Considerations. Journal of Consumer Culture, 11(1), 3-13.

Hamari, J., Sjöklint, M., \& Ukkonen, A. (2016). The sharing economy: Why people participate in collaborative consumption. Journal of the association for information science and technology, 67(9), 2047-2059.

Hand, M., Shove, E., \& Southerton, D. (2005). Explaining showering: A discussion of the material, conventional, and temporal dimensions of practice. Sociological Research Online, 10(2), 1-13.

Hargreaves, T. (2011). Practice-ing behavior change: Applying social practice theory to pro-environmental behavior change. Journal of consumer culture, 11(1), 79-99.

Heiskanen, E., \& Pantzar, M. (1997). Toward sustainable consumption: Two new perspectives. Journal of Consumer policy, 20(4), 409-442.

Helcom (2010). Ecosystem Health of the Baltic Sea. Holistic Assessment report from 2010. Baltic Sea Proceedings 155.

Hertwich, E. G. (2005). Life cycle approaches to sustainable consumption: a critical review. Environmental science \& technology, 39(13), 4673-4684.

Holbrook, M. B. (1987). What is consumer research?. Journal of Consumer Research, 14(1), 128-132. 
Holt, D. B. (2012). Constructing sustainable consumption: From ethical values to the cultural transformation of unsustainable markets. The ANNALS of the American Academy of Political and Social Science, 644(1), 236-255.

Huneke, M. E. (2005). The face of the un-consumer: An empirical examination of the practice of voluntary simplicity in the United States. Psychology \& Marketing, 22(7), 527-550.

ISO.14040 (1997), Environmental Managements Life Cycle Assessments Principles and Framework. Geneva, Switzerland: International Organization for Standardization.

Iyer, R., \& Muncy, J. A. (2009). Purpose and object of anti-consumption. Journal of Business Research, 62(2), 160-168.

Jackson, T. (2005). Live better by consuming less?: is there a "double dividend" in sustainable consumption?. Journal of Industrial Ecology, 9(1-2), 19-36.

Jacoby, J., Berning, C. K., \& Dietvorst, T. F. (1977). What about disposition? Journal of marketing, 41(2), 22-28.

Jaeger-Erben, M., Rückert-John, J., \& Schäfer, M. (2015). Sustainable consumption through social innovation: a typology of innovations for sustainable consumption practices. Journal of Cleaner Production, 108, 784-798.

Jensen Schau, H., \& Gilly, M. C. (2003). We are what we post? Self-presentation in personal web space. Journal of consumer research, 30(3), 385-404.

Jorgensen, D. L. 1989. Participant observation: A methodology for human studies (Applied social re- search methods series, vol. 15). Thousand Oaks, CA: Sage. Kaplan,

Kang, H. Y., \& Schoenung, J. M. (2005). Electronic waste recycling: A review of US infrastructure and technology options. Resources, Conservation and Recycling, 45(4), 368-400.

Keller, M., Halkier, B., \& Wilska, T. A. (2016). Policy and governance for sustainable consumption at the crossroads of theories and concepts. Environmental Policy and Governance, 26(2), 75-88.

Kilbourne, W. E., \& Beckmann, S. C. (1998). Review and critical assessment of research on marketing and the environment. Journal of Marketing Management, 14(6), 513-532.

Kilbourne, W., McDonagh, P., \& Prothero, A. (1997). Sustainable consumption and the quality of life: A macromarketing challenge to the dominant social paradigm. Journal of macromarketing, 17(1), 4-24.

Kirchherr, J., Piscicelli, L., Bour, R., Kostense-Smit, E., Muller, J., Huibrechtse-Truijens, A., \& Hekkert, M. (2018). Barriers to the circular economy: evidence from the European Union (EU). Ecological Economics, 150, 264-272.

Kirchherr, J., Reike, D., \& Hekkert, M. (2017). Conceptualizing the circular economy: An analysis of 114 definitions. Resources, Conservation and Recycling, 127, 221232.

Kjeldgaard, D., \& Ostberg, J. (2007). Coffee grounds and the global cup: Glocal consumer culture in Scandinavia. Consumption Markets \& Culture, 1O(2), 175-187.

Klein, J. G., Smith, N. C., \& John, A. (2004). Why we boycott: Consumer motivations for boycott participation. Journal of Marketing, 68(3), 92-109.

Kostecki, M. (1998). Marketing and the durable use of consumer goods: a framework for inquiry. The Durable Use of Consumer Products.

Kozinets, R. V. (2010). Netnography: ethnographic research in the age of the internet. Sage Publications Limited. 
Kozinets, R. V., \& Handelman, J. M. (2004). Adversaries of consumption: Consumer movements, activism, and ideology. Journal of consumer research, 31(3), 691704.

Lagerström, M., Strand, J., Eklund, B., \& Ytreberg, E. (2017). Total tin and organotin speciation in historic layers of antifouling paint on leisure boat hulls. Environmental pollution, 220, 1333-1341.

Lastovicka, J. L., \& Fernandez, K. V. (2005). Three paths to disposition: The movement of meaningful possessions to strangers. Journal of Consumer Research, 31(4), 813-823.

Lee, M. S., Dewhirst, T., \& Cherrier, H. (2018). Introduction to the Special Section: The Domain and Intersection of Anticonsumption, Marketing, and Public Policy.

Lee, M. S., Motion, J., \& Conroy, D. (2009). Anti-consumption and brand avoidance. Journal of Business Research, 62(2), 169-180.

Lofthouse, V. A., \& Prendeville, S. (2017). Considering the user in the circular economy. Delft University of Technology, 8, 10.

Lofthouse, V., \& Prendeville, S. (2018). Human-centred design of products and services for the circular economy-a review. The Design Journal, 21(4), 451-476.

Lubin, D. A., \& Esty, D. C. (2010). The sustainability imperative. Harvard business review, 88(5), 42-50.

Magaudda, P. (2011). When materiality 'bites back': Digital music consumption practices in the age of dematerialization. Journal of Consumer Culture, 11(1), 15-36.

McCracken, G. (1986). Culture and consumption: A theoretical account of the structure and movement of the cultural meaning of consumer goods. Journal of consumer research, 13(1), 71-84.

McDonagh, P., \& Prothero, A. (2014). Sustainability marketing research: Past, present and future. Journal of Marketing Management, 30(11-12), 1186-1219.

McMeekin, A., \& Southerton, D. (2012). Sustainability transitions and final consumption: practices and socio-technical systems. Technology Analysis \& Strategic Management, 24(4), 345-361.

Meadows, D., Randers, J., \& Meadows, D. (2004). A synopsis: Limits to growth: The 30-year update. Estados Unidos: Chelsea Green Publishing Company.

Mikkonen, I., \& Bajde, D. (2013). Happy Festivus! Parody as playful consumer resistance. Consumption Markets \& Culture, 16(4), 311-337.

Moisander, J. (2007). Motivational complexity of green consumerism. International journal of consumer studies, 31(4), 404-409.

Moisander, J., \& Valtonen, A. (2006). Qualitative marketing research: A cultural approach. Sage.

Moldan, B., Janoušková, S., \& Hák, T. (2012). How to understand and measure environmental sustainability: Indicators and targets. Ecological Indicators, 17, 4-13.

Moraes, C., Carrigan, M., \& Szmigin, I. (2012). The coherence of inconsistencies: Attitude-behavior gaps and new consumption communities. Journal of Marketing Management, 28(1-2), 103-128.

Mugge, R. (2017). A consumer's perspective on the circular economy. In Routledge Handbook of Sustainable Product Design (pp. 396-412). Routledge.

Murray, A., Skene, K., \& Haynes, K. (2017). The circular economy: an interdisciplinary exploration of the concept and application in a global context. Journal of Business Ethics, 140(3), 369-380.

Nielsen (2011).Sustainable efforts \& environmental concerns around the world.NewYork: The Nielsen Company. 
Norman, W., \& MacDonald, C. (2004). Getting to the bottom of "triple bottom line". Business ethics quarterly, 14(2), 243-262.

Packard, V. (1960). The Waste Makers, D. McKay Co., New York.

Phipps, M., \& Ozanne, J. L. (2017). Routines disrupted: Reestablishing security through practice alignment. Journal of Consumer Research, 44(2), 361-380.

Phipps, M., Ozanne, L. K., Luchs, M. G., Subrahmanyan, S., Kapitan, S., Catlin, J. R., ... \& Weaver, T. (2013). Understanding the inherent complexity of sustainable consumption: A social cognitive framework. Journal of Business Research, 66(8), 1227-1234.

Price, L. L., Arnould, E. J., \& Folkman Curasi, C. (2000). Older consumers' disposition of special possessions. Journal of Consumer Research, 27(2), 179-201.

Prothero, A., Dobscha, S., Freund, J., Kilbourne, W. E., Luchs, M. G., Ozanne, L. K., \& Thøgersen, J. (2011). Sustainable consumption: Opportunities for consumer research and public policy. Journal of Public Policy \& Marketing, 30(1), 31-38.

Reckwitz, A. (2002). Toward a theory of social practices: A development in culturalist theorizing. European journal of social theory, 5(2), 243-263.

Reisch, L. A., \& Th_gersen, J. (Eds.). (2015). Handbook of research on sustainable consumption. Edward Elgar Publishing.

Rizos, V., Rizos, V., Tuokko, K., Tuokko, K., Behrens, A., \& Behrens, A. (2017). The Circular Economy: A review of definitions, processes and impacts. CEPS Research Report No 2017/8, April 2017.

Røpke, I. (2009). Theories of practice - New inspiration for ecological economic studies on consumption. Ecological Economics, 68(10), 2490-2497.

Sahakian, M., \& Wilhite, H. (2014). Making practice theory practicable: Towards more sustainable forms of consumption. Journal of Consumer Culture, 14(1), 25-44.

Schatzki, T. (2002). The Site of the Social: A philosophical appraisal of the constitution of social life and change. University Park, PA: Pennsylvania State University Press.

Schatzki, T. R. (1987). Overdue analysis of Bourdieu's theory of practice. Inquiry, 30(12), 113-135.

Schatzki, T. R. (1996). Social practices: A Wittgensteinian approach to human activity and the social. Cambridge University Press.

Schau, H. J., Muñiz Jr, A. M., \& Arnould, E. J. (2009). How brand community practices create value. Journal of marketing, 73(5), 30-51.

Schau, H. J., Muñiz Jr, A. M., \& Arnould, E. J. (2009). How brand community practices create value. Journal of marketing, 73(5), 30-51.

Schouten, J. W., \& McAlexander, J. H. (1995). Subcultures of consumption: An ethnography of the new bikers. Journal of consumer research, 22(1), 43-61.

Scott, K. A., \& Weaver, S. T. (2018). The Intersection of Sustainable Consumption and Anticonsumption: Repurposing to Extend Product Life Spans. Journal of Public Policy \& Marketing, 37(2), 291-305.

Scott, R., Cayla, J., \& Cova, B. (2017). Selling pain to the saturated self. Journal of Consumer Research, 44(1), 22-43.

Selvefors, A., Rexfelt, O., Renström, S., \& Strömberg, H. (2019). Use to use-A user perspective on product circularity. Journal of Cleaner Production, 223, 10141028.

Sherry, J. F. (2008). The ethnographer's apprentice: Trying consumer culture from the outside in. Journal of Business Ethics, 80(1), 85-95.

Shove, E. (2010). Beyond the ABC: climate change policy and theories of social change. Environment and planning A, 42(6), 1273-1285. 
Shove, E. \& Pantzar M. (2005). Consumers, producers and practices: Understanding the invention and reinvention of Nordic walking. Journal of Consumer Culture, 5 (1), 43-64.

Shove, E., Pantzar, M., \& Watson, M. (2012). The dynamics of social practice: Everyday life and how it changes. Sage.

Slaper, T. F., \& Hall, T. J. (2011). The triple bottom line: What is it and how does it work. Indiana business review, 86(1), 4-8.

Slater, D. (1998). Consumer culture and modernity, Cambridge. UK: Polity.

Spaargaren G. (2011). Theories of practices: Agency, technology, and culture exploring the relevance of practice theories for the governance of sustainable consumption practices in the new world-order. Global Environmental Change, 21, 813-822.

Spaargaren, G. (2003). Sustainable consumption: a theoretical and environmental policy perspective. Society \&Natural Resources, 16(8), 687-701.

Spiggle, S. (1994). Analysis and interpretation of qualitative data in consumer research. Journal of consumer research, 21(3), 491-503.

Spotswood, F., Chatterton, T., Tapp, A., \& Williams, D. (2015). Analyzing cycling as a social practice: An empirical grounding for behavior change. Transportation research part F: traffic psychology and behavior, 29, 22-33.

Spring, M., \& Araujo, L. (2017). Product biographies in servitization and the circular economy. Industrial Marketing Management, 60, 126-137.

Stern, P. C. (2000). New environmental theories: toward a coherent theory of environmentally significant behavior. Journal of social issues, 56(3), 407-424.

Swidler, A. (2001). What Anchors Cultural Practices, in Schatzki, T., ed. The Practice Turn in Contemporary Theory, London: Routledge, 74-92.

Takata, Shozo, Fumihiko Kirnura, Fred J.A.M. van Houten, Engelbert Westkamper, Moshe Shpitalni, M., Darek Ceglarek, and Jay Lee (2004), Maintenance: changing role in life cycle management, CIRP Annals, 53 (2), 643-655.

Thomas, K. V., \& Brooks, S. (2010). The environmental fate and effects of antifouling paint biocides. Biofouling, 26(1), 73-88.

Thomas, T. C., \& Epp, A. M. (2019). The Best Laid Plans: Why New Parents Fail to Habituate Practices. Journal of Consumer Research.

Thouvenin, M.; Peron, J.J. ; Charreteur, C. ; Guerin, P. ; Langlois, J.Y., et al. (2002). A study of the biocide release from antifouling paints. Progress in Organic Coatings, $475-83$.

Thøgersen, J. (2005). How may consumer policy empower consumers for sustainable lifestyles?. Journal of consumer policy, 28(2), 143-177.

Tian, K., \& Belk, R. W. (2005). Extended self and possessions in the workplace. Journal of consumer research, 32(2), 297-310.

Türe, M. (2014). Value-in-disposition: Exploring how consumers derive value from disposition of possessions. Marketing Theory, 14(1), 53-72.

UNEP (United Nations Environment Programme) (2012), Responsible Resource Management for a Sustainable World: Findings from the International Resource Panel, Paris: International Resource Panel, United Nations Environment Programme.

United Nations (1993), Agenda 21: Earth Summit - The United Nations Programme of Action from Rio, New Yourk: United Nations.

United Nations, (2016). Transforming Our World: the 2030 Agenda for Sustainable Development, A/RES/70/1. United Nations Office, Geneva, Switzerland.

UNO (2002). Plan of Implementation of the World Summit on Sustainable Development. A/CONF. 199/20. New York: United Nations Organisations. 
Van den Berg, M. R., \& Bakker, C. A. (2015). A product design framework for a circular economy. Product Lifetimes And The Environment.

Van den Brande, K., Happaerts, S., \& Bouteligier, S. (2011). Keeping the sustainable development flame alive. The Broker, $1-4$.

Verbeek, P. P., \& Kockelkoren, P. (1998). The things that matter. Design Issues, 14(3), 28-42.

Vermeir, I., \& Verbeke, W. (2006). Sustainable food consumption: Exploring the consumer "attitude-behavioral intention" gap. Journal of Agricultural and Environmental ethics, 19(2), 169-194.

Vermeir, I., \& Verbeke, W. (2006). Sustainable Food Consumption: Exploring the Consumer "Attitude - Behavioral Intention" Gap. Journal of Agricultural and Environmental Ethics, 19(2), 169-194.

Verplanken, B., \& Roy, D. (2016). Empowering interventions to promote sustainable lifestyles: Testing the habit discontinuity hypodissertation in a field experiment. Journal of Environmental Psychology, 45, 127-134.

Wang, Z., Zhang, B., Yin, J., \& Zhang, X. (2011). Willingness and behavior towards ewaste recycling for residents in Beijing city, China. Journal of Cleaner Production, 19(9-10), 977-984.

Warde, A. (2005). Consumption and Theories of Practice. Journal of Consumer Culture, 5(2), pp.131-153.

Wastling, T., Charnley, F., \& Moreno, M. (2018). Design for circular behavior: considering users in a circular economy. Sustainability, 10(6), 1743.

Watson, M., \& Shove, E. (2008). Product, competence, project and practice: DIY and the dynamics of craft consumption. Journal of Consumer Culture, 8(1), 69-89.

WCED, S. W. S. (1987). World Commission on Environment and Development. In Our Common Future (1-91). New York, NY: Oxford University Press.

Welch, D. (2017). Consumption and teleoaffective formations: consumer culture and commercial communications. Journal of Consumer Culture.

Welch, D., \& Warde, A. (2015). Theories of practice and sustainable consumption. Handbook of research on sustainable consumption, 84-100.

Wijetunga, D. (2019). "Throwaway" consumption in a consumerist society: Evidence from a developing country. Business Strategy \& Development.

Wilhite, H. (2008). New thinking on the agentive relationship between end-use technologies and energy-using practices. Energy Efficiency, 1(2), 121-130.

Woermann, N., \& Rokka, J. (2015). Timeflow: How consumption practices shape consumers' temporal experiences. Journal of Consumer Research, 41(6), 14861508.

Yebra, D.M.; Kiil, S.; Dam-Johansen, K. (2004). Antifouling technology-- past, present and future steps towards efficient and environmentally friendly antifouling coatings. Progress in Organic Coatings, 50(2), 75-104.

Ylä-Mella, J., Keiski, R. L., \& Pongrácz, E. (2015). Electronic waste recovery in Finland: Consumers' perceptions towards recycling and re-use of mobile phones. Waste Management, 45, 374-384.

Yngfalk, C. (2016). Bio-politicizing consumption: neo-liberal consumerism and disembodiment in the food marketplace. Consumption Markets \& Culture, 19(3), 275295.

Young, W., \& Middlemiss, L. (2012). A rethink of how policy and social science approach changing individuals' actions on greenhouse gas emissions. Energy Policy, 41, 742-747. 
Young, W., Hwang, K., McDonald, S., \& Oates, C. J. (2010). Sustainable consumption: green consumer behavior when purchasing products. Sustainable development, 18(1), 20-31.

Østergaard, P., Linnet, J. T., Andersen, L. P., Kjeldgaard, D., Bjerregaard, S., Weijo, H., ... \& Östberg, J. (2014). Nordic consumer culture: Context and concept. In Consumer Culture Theory (pp. 245-257). Emerald Group Publishing Limited. 
ISBN 978-952-60-8884-6 (printed)

馬 ISBN 978-952-60-8885-3 (pdf)

$\infty \overline{\overline{\bar{\equiv}}}$ ISSN 1799-4934 (printed)

ज韭 ISSN 1799-4942 (pdf)

Q

$\stackrel{\infty}{\overline{2}}$

Aalto University

School of Business 